\title{
Percentile curves for skinfold thickness for Canadian children and youth
}

\author{
Stefan Kuhle ${ }^{\text {Corresp.. }}{ }^{1}$, Jillian Ashley-Martin ${ }^{1}{ }^{\text {, }}$ Bryan Maguire ${ }^{2}$, David C Hamilton ${ }^{2}$ \\ 1 Departments of Pediatrics and Obstetrics \& Gynaecology, Dalhousie University, Halifax, NS, Canada \\ 2 Department of Mathematics \& Statistics, Dalhousie University, Halifax, NS, Canada \\ Corresponding Author: Stefan Kuhle \\ Email address: stefan.kuhle@dal.ca
}

Background: Skinfold thickness (SFT) measurements are a reliable and feasible method for assessing body fat in children but their use and interpretation is hindered by the scarcity of reference values in representative populations of children. The objective of the present study was to develop age- and sex-specific percentile curves for five SFT measures (biceps, triceps, subscapular, suprailiac, medial calf) in a representative population of Canadian children and youth. Methods: We analyzed data from 3938 children and adolescents between 6 and 19 years of age who participated in the Canadian Health Measures Survey cycles 1 (2007/2009) and 2 (2009/2011). Standardized procedures were used to measure SFT. Age- and sex-specific centiles for SFT were calculated using the GAMLSS method. Results: Percentile curves were materially different in absolute value and shape for boys and girls. Percentile girls in girls steadily increased with age whereas percentile curves in boys were characterized by a pubertal centered peak. Conclusions: The current study has presented for the first time percentile curves for five SFT measures in a representative sample of Canadian children and youth. 
1 Percentile curves for skinfold thickness for Canadian children and youth

2 Stefan Kuhle* (stefan.kuhle@dal.ca)

3 Depts. of Pediatrics and Obstetrics \& Gynaecology, Dalhousie University, Halifax, NS, Canada

4

5 Jillian Ashley-Martin (jillian.ashley-martin@dal.ca)

6 Depts. of Pediatrics and Obstetrics \& Gynaecology, Dalhousie University, Halifax, NS, Canada

7

8 Bryan Maguire (bryanmaguire@live.ca)

9 Dept. of Mathematics \& Statistics, Dalhousie University, Halifax, NS, Canada

10

11 David Hamilton (david.hamilton@dal.ca)

12 Dept. of Mathematics \& Statistics, Dalhousie University, Halifax, NS, Canada

13

$14 *$ Corresponding author:

15 IWK Health Centre, Perinatal Epidemiology Research Unit

165980 University Avenue, Halifax, NS B3K 6R8, Canada

17

18 


\section{ABSTRACT}

20 Background: Skinfold thickness (SFT) measurements are a reliable and feasible method for

21 assessing body fat in children but their use and interpretation is hindered by the scarcity of

22 reference values in representative populations of children. The objective of the present study was

23 to develop age- and sex-specific percentile curves for five SFT measures (biceps, triceps,

24 subscapular, suprailiac, medial calf) in a representative population of Canadian children and

25 youth. Methods: We analyzed data from 3938 children and adolescents between 6 and 19 years

26 of age who participated in the Canadian Health Measures Survey cycles $1(2007 / 2009)$ and 2

27 (2009/2011). Standardized procedures were used to measure SFT. Age- and sex-specific centiles

28 for SFT were calculated using the GAMLSS method. Results: Percentile curves were materially

29 different in absolute value and shape for boys and girls. Percentile curves in girls steadily

30 increased with age whereas percentile curves in boys were characterized by a pubertal centered

31 peak. Conclusions: The current study has presented for the first time percentile curves for five

32 SFT measures in a representative sample of Canadian children and youth. 


\section{INTRODUCTION}

36 The rising prevalence of overweight and obese children and associated public health toll in

37 Canada and other developed countries is well established (1-3). Effective obesity prevention and

38 treatment efforts require reliable identification of the at risk population. Specifically, accurate

39 characterization of childhood body composition is essential for identifying children who

40 currently exceed recommended weight norms or may be at risk of future excess weight and

41 related cardiovascular and metabolic health conditions. Though body mass index is the most

42 commonly used method for assessing childhood body composition, it does not provide an

43 accurate estimate of adiposity $(4,5)$. Childhood adiposity is potentially more strongly associated

44 with future body composition and metabolic status than childhood BMI $(6,7)$. Childhood

45 adiposity is also positively associated with certain cardiovascular and metabolic disease risk

46 factors $(8,9)$. Skinfold thickness (SFT) measures are a feasible and reliable estimate of body fat

47 (10-12), and have been shown to be predictive of elevated levels of cardiovascular disease risk

48 factors $(13,14)$ and metabolic syndrome $(15)$. Interpretation and uptake of SFT measurement as

49 a method for the assessment of body fat is hindered by the lack of reference data. While there are

50 health-related cutoffs for BMI $(16,17)$, waist circumference (18), and waist-to-height ratio (19),

51 there is no comparable definition based on SFT for either children or adults. Percentile curves

52 have been developed for US $(15,20)$ and European $(21-28)$ children. The applicability of these

53 values to the Canadian population is limited due to differences in childhood overweight and

54 obesity prevalence. Moreover, previous SFT references have either been developed with a

55 limited number of skinfolds $(15,20,24,25)$ or were based on a narrower age range $(21,23,29)$.

56 Therefore, the objective of the present study was to develop age- and sex-specific percentile 
57 curves for five SFT measures (biceps, triceps, subscapular, suprailiac, medial calf) in a

58 representative population of Canadian children and youth.

59

\section{METHODS}

61 The present study used data from the Canadian Health Measures Survey (CHMS) cycles 1 and 2.

62 The CMHS is a representative, cross-sectional survey that assesses indicators of health and

63 wellness in Canadians between 3 and 79 years $(30,31)$. The survey consists of a household

64 interview to obtain sociodemographic and health information, and a visit to a mobile

65 examination centre to perform a number of physical measurements and tests. The sampling

66 frame of the Canadian Labour Force Survey was used to identify the collection sites for the

67 mobile examination centres. Within each collection site, households were selected using the

682006 Census as the sampling frame. Interviews and examinations for the CHMS Cycle 1 and 2

69 were performed between 2007 and 2009, and 2009 and 2011, respectively. The overall response

70 rate in the two cycles was $51.7 \%$ and $55.7 \%$, respectively. Data from the two cycles was

71 combined as per Statistics Canada guidelines (32) and weighted to account for the design effect

72 and non-response bias (32). A total of 11,999 persons participated in the physical examination

73 part of the survey. The present analysis uses data from 3938 children and adolescents (1996

74 males and 1942 females) between the ages of 6 and 19 years.

75

\section{Anthropometric measures}

77 Body mass index was calculated from measured weight and height using the formula

78 weight $/$ height $^{2}\left[\mathrm{~kg} / \mathrm{m}^{2}\right]$. Weight was measured using a calibrated digital scale (Mettler Toledo,

79 Mississauga, ON, Canada) to the nearest $0.1 \mathrm{~kg}$. Standing height was measured using a fixed 
80 stadiometer with a vertical backboard and a moveable headboard to the nearest $0.01 \mathrm{~cm}$. Weight

81 status (underweight, normal weight, overweight, obese) was determined based on the IOTF

82 (International Obesity Task Force) growth reference (33). All SFT measurements were

83 performed by trained health professionals at the mobile examination centres using a Harpenden

84 skinfold caliper to the nearest $0.2 \mathrm{~mm}$. Each SFT was measured three times and the average of

85 the three measurements was used. Triceps SFT was measured on the midline of the back of the

86 arm at the mid-point level between the acromium process and the tip of the olecranon process.

87 Biceps SFT was measured over the biceps at the same level as the midpoint for the triceps.

88 Subscapular SFT was measured below the inferior angle of the scapula at an angle of 45 degrees

89 to the spine. Suprailiac SFT was measured in the mid-axillary line above the crest of the ilium.

90 Medial calf SFT was measured at the medial side of the calf at the point of the largest

91 circumference. SFT measurements were not done on individuals with a BMI $\geq 30 \mathrm{~kg} / \mathrm{m}^{2}$.

92

93 Statistical analysis

94 The data were split by sex and modeled using a four parameter $(\mu, \sigma, v, \tau)$ Box-Cox power

95 exponential distribution (34). The GAMLSS method is an extension of the LMS method

96 developed by Cole and Green (35) and assumes that when the data (Y) is transformed using the

97 transformation:

$$
\begin{array}{cc}
z=\frac{(y / \mu)^{\nu}-1}{\nu \sigma} & v \neq 0 \\
z=\frac{\log _{e}(y / \mu)}{\sigma} & v=0
\end{array}
$$


101 The age-specific distribution expresses the mean, coefficient of variation, skewness, and kurtosis

102 as parameters that change smoothly as a function of age by modeling them as cubic splines.

103 These functions can be plotted as smooth curves in terms of age and are referred to as the $\mu$

104 (mean), $\sigma$ (variance), $v$ (skewness), and $\tau$ (kurtosis) curves. Centiles for a particular age are

105 computed by using the values of the four parameters for the corresponding age. The $3^{\text {rd }}, 10^{\text {th }}$,

$10625^{\text {th }}, 50^{\text {th }}, 75^{\text {th }}, 90^{\text {th }}$, and $97^{\text {th }}$ centile curves were computed for biceps, triceps, subscapular,

107 suprailiac, and medial calf SFT.

108 To avoid unusual behaviours of the spline functions near the end of the age range, data from

109 respondents up to age 30 years were used to fit the models. This modification produced smoother

110 curves that more accurately reflect the population characteristics. Residual quantile plots ("worm

111 plots") (36) were used to assess the goodness of fit of each component of the models.

112 All calculations were performed using the sampling weights provided by Statistics Canada (32)

113 to account for design effect and non-response bias. The CHMS uses a multistage sampling

114 design with two sampling frames to select its sample. The probability of an individual to be

115 selected for the survey is determined as the product of the probability of selection at each stage.

116 To correct for non-response, the weight of non-respondent households and individuals is

117 redistributed to respondents within homogeneous response groups based on characteristics that

118 are available for both respondents and non-respondents as determined from the Census of

119 Canada (such as dwelling type or household income). A detailed description of the weighting

120 procedure can be found elsewhere (31).

121 The statistical software package R (37) with the gamlss package (38) was used to perform the

122 statistical analyses. 


\section{Ethics}

125 All processes used for cycles 1 and 2 of the CHMS were reviewed and approved by the Health

126 Canada Research Ethics Board to ensure that internationally recognized ethical standards for

127 human research were met and maintained. Written informed consent was obtained from all

128 participants aged 14 years and older; parents or guardians gave consent on behalf of children

129 aged 6 to 13 years, while the child provided his or her assent to participate $(30,31)$. The current

130 project was approved by the IWK Health Centre Research Ethics Board, Halifax, NS, Canada

131 (File \# 1014413).

132

133 RESULTS

134 Characteristics of the sample are shown in Table 1. The median and interquartile range for the

135 five SFT measurements by age and sex are shown in Table 2 . The parameter values $(\mu, \sigma, v, \tau)$ as

136 well as the $3^{\text {rd }}, 10^{\text {th }}, 25^{\text {th }}, 50^{\text {th }}, 75^{\text {th }}, 90^{\text {th }}$, and $97^{\text {th }}$ percentiles for the SFT curves are presented by

137 age and sex (Tables 3-7). Model diagnostics showed an adaequate fit for all models.

138 Percentile curves are materially different in both absolute values and shape for boys and girls

139 (Figures 1-5). Girls have higher median skinfold thickness than boys at all measurement sites

140 (Table 2). All skinfold thickness measurements among girls are characterized by a relatively

141 steady increase from childhood through adolescence despite differing absolute percentile values

142 and rates of yearly change. Lower body (medial calf, suprailiac) skinfold thickness

143 measurements steadily rise until adolescence at which point the rate of yearly increase

144 diminishes. Among upper body measurements, the biceps percentile curve plateaus in early

145 adolescence, whereas the triceps and subscapular curves steadily increase from age 6 to 19 . No 
146 substantial differences in truncal (subscapular, suprailiac) and peripheral (triceps, biceps, calf)

147 percentile curves among girls were observed.

148 Skinfold thickness curves in boys are characterized by a peak around age 12 years. The

149 magnitude of this pubertal centered peak was most notable in the percentiles exceeding the

150 median. Subsequent to the post-pubertal peak, skinfold thickness decreased in the peripheral

151 measures (biceps, calf, triceps) and moderately increased in the truncal measures. There were no

152 apparent distinguishing characteristics between the upper and lower body percentile curves in 153 boys.

154

155 DISCUSSION

156 The current study has presented for the first time percentile curves for five SFT measures based

157 on a representative sample of Canadian children and youth aged 6 to 19 years. The percentile

158 curves presented are meant to be descriptive rather than prescriptive as associations with

159 cardiovascular disease markers or outcomes were not assessed. The data may be used by

160 researchers as reference data for future studies.

161

162 Our findings are comparable with other studies that have examined the development of SFT in

163 childhood and adolescence. Both the steady upward trend in girls and the pubertal peak in boys

164 were also observed in US (20), German (23, 25, 39), Polish (26), and Norwegian children (24).

165 Of note, the pubertal peak was less pronounced in samples with a narrower age ranges $(21,23-$

166 25). The absolute SFT values in our study were largely comparable to US data of 32,783 children

167 ages 1 to 19 years collected between 1963-1994 (20): Median triceps and subscapular SFT at age

16812 years were comparable between girls in the CHMS (triceps: $13.5 \mathrm{~mm}$; subscapular: $8.8 \mathrm{~mm}$ ) 
169 and the US study (triceps: $13.1 \mathrm{~mm}$; subscapular: $8.2 \mathrm{~mm}$ ). Median triceps SFT at age 12 in

170 CHMS boys was slightly lower than reported in US boys (11.3 mm vs. $13.1 \mathrm{~mm})$ whereas

171 median subscapular SFT was slightly higher in the CHMS than in the US sample (7.1 mm vs. 6.0

$172 \mathrm{~mm})$. These differences may be due to heterogeneity in timing of data collection, ethnic

173 distribution, and statistical methodology (LMS vs. GAMLSS) between the two studies.

174 Comparison with SFT in adults is a challenge due to the scarcity of adult SFT data. Data from

175 adults in the NHANES recruited between 1971 and 1974 shows that median subscapular SFT

176 values in the youngest adult age category (ages 18-24 years) were moderately higher than

177 median values at age 18 years among CHMS participants (males 11.0 vs. $9.0 \mathrm{~mm}$, females 13.0

178 vs. $12.4 \mathrm{~mm}$ ) (40). Considering that the NHANES data was collected prior to the obesity

179 epidemic, the higher SFT in the US sample is unexpected. It is possible that these differences

180 reflect the higher rate of obesity in the US compared to Canada (3) or the use of a broader age

181 category and the influence of increasing SFT in early adulthood.

182

183 Skinfold thickness measurements are frequently used to derive an estimate of body fat

184 percentage $(15,23,41)$. One of the most commonly used estimation equations for this purpose

185 was developed by Slaughter et al. and predicts body fat from triceps and subscapular SFT (42).

186 However, while the simplicity of these equations is very appealing, they are based on a historical

187 population and their validity for use in contemporary populations is questionable (43) as

188 evidenced by the bias when compared with methods like dual-energy X-ray absorptiometry (41,

$18944,45)$. Moreover, reference data for directly measured body fat using criterion methods are now

190 available $(21,46,47)$ that allow for accurate assessment of the development of lean and fat mass

191 in children. It should also be acknowledged in this context that SFT inherently only measures 
192 external fat and can not assess internal visceral adiposity, which is most strongly associated with

193 health outcomes (48). However, SFT show good correlations with elevated levels of

194 cardiovascular disease risk factors $(13,14)$ and metabolic syndrome $(15)$.

195

196 To our knowledge, only one study employed the GAMLSS method (34) like we did to model

197 SFT percentiles. The authors of this multicentre European study derived SFT percentile curves

198 for 18,745 children ages 2 to 10 years but excluded overweight, obese, and underweight children

199 from the analysis (28). Thus, a direct comparison of their findings with ours is not feasible. The

200 LMS method (35) has become the most popular choice for modeling percentiles curves for

201 anthropometric measures due to its ease of use, adoption by the World Health Organization (49),

202 and the availability of a simple software tool (LMSchartmaker, Harlow Healthcare, UK) to

203 generate the curves. In a recent analysis of the same sample of children, we generated percentile

204 curves for BMI, waist circumference, waist-to-height ratio, and sum of five skinfolds with an

205 adaequate model fit using the LMS method (50). However, when using the 3-parameter LMS

206 method for the individual SFT measurements in the present study, the diagnostic worm plots

207 revealed a large amount of kurtosis present for some variables. The LMS method attempted to

208 account for the kurtosis with skewness, which lead to a poorer model fit at the tail end of the

209 distribution. By contrast, the GAMLSS method includes a $4^{\text {th }}$ parameter to allow the explicit

210 modeling of kurtosis as a function of age. Diagnostics showed no model inadequacies when the

211 curves were constructed using the GAMLSS method. Future studies should consider using the

212 GAMLSS method if the model fit using an LMS approach is not adaequate.

213 
214 The strengths of the current study include the nationally representative sample of children and

215 youth, and the use of sample weighting to account for non-response and design effect. The

216 availability of a wide age range in the CHMS study population allowed us to visualize growth

217 related trends that were not apparent in studies with narrower age ranges $(21,23,24)$. We did

218 not exclude overweight or obese children as the objective of the present study was to describe

219 body fatness measures in a representative population of Canadian children rather than to attempt

220 to describe what may constitute normal percentile values. Due to the physical burden of the

221 assessments used in the survey, and the need to travel to the mobile examination clinics, there

222 may have been a self-selection toward more mobile, healthier, and fitter individuals. Our study is

223 limited by the relatively small sample size, and the cross-sectional nature of the data;

224 longitudinal data may more accurately reflect how body fatness changes with age. The omission

225 of SFT measurements in children with a BMI greater than 30 resulted in an exclusion of $4 \%$ of

226 children, which may have resulted in a slight downward shift of the percentiles compared to the

227 full sample. While the flexibility of the GAMLSS method is a notable strength, its flexibility also

228 means that the curves may differ considerably based on the parameter choices made by the

229 researcher.

230

231 This study has presented percentile curves for SFT in a representative sample of Canadian

232 children and youth. Since we did not examine any relationships with health outcomes or disease

233 markers, the data should be considered as a reference for future studies and not as a growth

234 standard.

235

236 ACKNOWLEDGEMENTS 
237 The analysis presented in this paper was conducted at the Atlantic Research Data Centre, which

238 is part of the Canadian Research Data Centre Network (CRDCN). The services and activities

239 provided by the Atlantic Research Data Centre are made possible by the financial or in-kind

240 support of the SSHRC, the CIHR, the CFI, Statistics Canada, and Dalhousie University. The

241 views expressed in this paper do not necessarily represent the views of the CRDCN or its

242 partners.

243

\section{REFERENCES}

245 1. Shields M. Overweight and obesity among children and youth. Health Rep 2006; 17: $27-$

$246 \quad 42$

247 2. Tran BX, Nair AV, Kuhle S, Ohinmaa A, Veugelers PJ. Cost analyses of obesity in 248 Canada: scope, quality, and implications. Cost Eff Resour Alloc 2013; 11: 3. DOI: $249 \quad 10.1186 / 1478-7547-11-3$.

250 3. Ng M, Fleming T, Robinson M, Thomson B, Graetz N, Margono C, Mullany EC, Biryukov S, Abbafati C, Abera SF, Abraham JP, Abu-Rmeileh NM, Achoki T, AlBuhairan FS, Alemu ZA, Alfonso R, Ali MK, Ali R, Guzman NA, Ammar W, Anwari P, Banerjee A, Barquera S, Basu S, Bennett DA, Bhutta Z, Blore J, Cabral N, Nonato IC, Chang JC, 254 Chowdhury R, Courville KJ, Criqui MH, Cundiff DK, Dabhadkar KC, Dandona L, Davis A, Dayama A, Dharmaratne SD, Ding EL, Durrani AM, Esteghamati A, Farzadfar F, Fay DF, Feigin VL, Flaxman A, Forouzanfar MH, Goto A, Green MA, Gupta R, Hafezi-Nejad N, Hankey GJ, Harewood HC, Havmoeller R, Hay S, Hernandez L, Husseini A, Idrisov BT, Ikeda N, Islami F, Jahangir E, Jassal SK, Jee SH, Jeffreys M, Jonas JB, Kabagambe EK, Khalifa SE, Kengne AP, Khader YS, Khang YH, Kim D, Kimokoti RW, Kinge JM, 
260 Kokubo Y, Kosen S, Kwan G, Lai T, Leinsalu M, Li Y, Liang X, Liu S, Logroscino G,

261 Lotufo PA, Lu Y, Ma J, Mainoo NK, Mensah GA, Merriman TR, Mokdad AH,

262 Moschandreas J, Naghavi M, Naheed A, Nand D, Narayan KM, Nelson EL, Neuhouser

263 ML, Nisar MI, Ohkubo T, Oti SO, Pedroza A, Prabhakaran D, Roy N, Sampson U, Seo H,

264 Sepanlou SG, Shibuya K, Shiri R, Shiue I, Singh GM, Singh JA, Skirbekk V, Stapelberg

265 NJ, Sturua L, Sykes BL, Tobias M, Tran BX, Trasande L, Toyoshima H, van de Vijver S,

266 Vasankari TJ, Veerman JL, Velasquez-Melendez G, Vlassov VV, Vollset SE, Vos T, Wang

267 C, Wang X, Weiderpass E, Werdecker A, Wright JL, Yang YC, Yatsuya H, Yoon J, Yoon

268 SJ, Zhao Y, Zhou M, Zhu S, Lopez AD, Murray CJ, Gakidou E. Global, regional, and

269 national prevalence of overweight and obesity in children and adults during 1980-2013: a

$270 \quad$ systematic analysis for the Global Burden of Disease Study 2013. Lancet 2014; 384: 766-

271781

272 4. Frankenfield DC, Rowe WA, Cooney RN, Smith JS, Becker D. Limits of body mass index

273 to detect obesity and predict body composition. Nutrition 2001; 17: 26-30.

274 5. Brambilla P, Bedogni G, Moreno LA, Goran MI, Gutin B, Fox KR, Peters DM, Barbeau P,

275 De Simone M, Pietrobelli A. Crossvalidation of anthropometry against magnetic resonance

276 imaging for the assessment of visceral and subcutaneous adipose tissue in children. Int J

277 Obes (Lond) 2006; 30: 23-30.

278 6. Freedman DS, Serdula MK, Srinivasan SR, Berenson GS. Relation of circumferences and

279 skinfold thicknesses to lipid and insulin concentrations in children and adolescents: the

280 Bogalusa Heart Study. Am J Clin Nutr 1999; 69: 308-317.

281 7. Nooyens AC, Koppes LL, Visscher TL, Twisk JW, Kemper HC, Schuit AJ, van Mechelen

282 W, Seidell JC. Adolescent skinfold thickness is a better predictor of high body fatness in 
283 adults than is body mass index: the Amsterdam Growth and Health Longitudinal Study. Am $284 \quad$ J Clin Nutr 2007; 85: 1533-1539.

285 8. Going SB, Lohman TG, Cussler EC, Williams DP, Morrison JA, Horn PS. Percent body fat 286 and chronic disease risk factors in U.S. children and youth. Am J Prev Med 2011; 41: S7728786.

288 9. Dai S, Fulton JE, Harrist RB, Grunbaum JA, Steffen LM, Labarthe DR. Blood lipids in 289 children: age-related patterns and association with body-fat indices: Project HeartBeat. $\mathrm{Am}$ $290 \quad$ J Prev Med 2009; 37: S56-64.

291 10. Boeke CE, Oken E, Kleinman KP, Rifas-Shiman SL, Taveras EM, Gillman MW. 292 Correlations among adiposity measures in school-aged children. BMC Pediatr 2013; 13 : 293 99. DOI: $10.1186 / 1471-2431-13-99$.

294 11. Sardinha LB, Going SB, Teixeira PJ, Lohman TG. Receiver operating characteristic 295 analysis of body mass index, triceps skinfold thickness, and arm girth for obesity screening 296 in children and adolescents. Am J Clin Nutr 1999; 70: 1090-1095.

12. Bedogni G, Iughetti L, Ferrari M, Malavolti M, Poli M, Bernasconi S, Battistini N. Sensitivity and specificity of body mass index and skinfold thicknesses in detecting excess adiposity in children aged 8-12 years. Ann Hum Biol 2003; 30: 132-139.

13. Steinberger J, Jacobs DR, Raatz S, Moran A, Hong CP, Sinaiko AR. Comparison of body 301 fatness measurements by BMI and skinfolds vs dual energy X-ray absorptiometry and their relation to cardiovascular risk factors in adolescents. Int J Obes (Lond) 2005; 29: 13461352.

14. Petkeviciene J, Klumbiene J, Kriaucioniene V, Raskiliene A, Sakyte E, Ceponiene I. Anthropometric measurements in childhood and prediction of cardiovascular risk factors in 
306 adulthood: Kaunas cardiovascular risk cohort study. BMC Public Health 2015; 15: 218.

307 DOI: $10.1186 / \mathrm{s} 12889-015-1528-5$.

308 15. Laurson KR, Eisenmann JC, Welk GJ. Body fat percentile curves for U.S. children and $309 \quad$ adolescents. Am J Prev Med 2011; 41: S87-92.

310 16. Cole TJ, Bellizzi MC, Flegal KM, Dietz WH. Establishing a standard definition for child 311 overweight and obesity worldwide: international survey. BMJ 2000; 320: 1240-1243.

312 17. de Onis M, Onyango AW, Borghi E, Siyam A, Nishida C, Siekmann J. Development of a WHO growth reference for school-aged children and adolescents. Bull World Health Organ 2007; 85: 660-667.

18. World Health Organization. 2008. Waist circumference and waist-hip ratio: report of a WHO expert consultation. Available at http://www.who.int/nutrition/publications/obesity/WHO report waistcircumference and waisthip ratio/en/ (accessed June 20, 2016).

19. McCarthy HD, Ashwell M. A study of central fatness using waist-to-height ratios in UK children and adolescents over two decades supports the simple message--'keep your waist circumference to less than half your height'. Int J Obes (Lond) 2006; 30: 988-992.

322

20. Addo OY, Himes JH. Reference curves for triceps and subscapular skinfold thicknesses in US children and adolescents. Am J Clin Nutr 2010; 91: 635-642.

21. Moreno LA, Mesana MI, González-Gross M, Gil CM, Ortega FB, Fleta J, Wärnberg J, León J, Marcos A, Bueno M. Body fat distribution reference standards in Spanish adolescents: the AVENA Study. Int J Obes (Lond) 2007; 31: 1798-1805.

327 22. Heude B, Kettaneh A, de Lauzon Guillain B, Lommez A, Borys JM, Ducimetière P, 328 Charles MA, Fleurbaix LVSG. Growth curves of anthropometric indices in a general 
population of French children and comparison with reference data. Eur J Clin Nutr 2006; 60: $1430-1436$.

331

23. Haas GM, Liepold E, Schwandt P. Percentile curves for fat patterning in German adolescents. World J Pediatr 2011; 7: 16-23.

24. Brannsether B, Roelants M, Bjerknes R, Júlíusson PB. References and cutoffs for triceps and subscapular skinfolds in Norwegian children 4-16 years of age. Eur J Clin Nutr 2013; 67: 928-933.

25. Kromeyer-Hauschild K, Glässer N, Zellner K. Percentile curves for skinfold thickness in 7to 14-year-old children and adolescents from Jena, Germany. Eur J Clin Nutr 2012; 66: 613-621.

26. Jaworski M, Kułaga Z, Płudowski P, Grajda A, Gurzkowska B, Napieralska E, Swiąder A, Pan H, Litwin M, Olaf SG. Population-based centile curves for triceps, subscapular, and abdominal skinfold thicknesses in Polish children and adolescents--the OLAF study. Eur J Pediatr 2012; 171: 1215-1221.

27. Wohlfahrt-Veje C, Tinggaard J, Winther K, Mouritsen A, Hagen CP, Mieritz MG, de Renzy-Martin KT, Boas M, Petersen JH, Main KM. Body fat throughout childhood in 2647 healthy Danish children: agreement of BMI, waist circumference, skinfolds with dual Xray absorptiometry. Eur J Clin Nutr 2014; 68: 664-670.

28. Nagy P, Kovacs E, Moreno LA, Veidebaum T, Tornaritis M, Kourides Y, Siani A, Lauria F, Sioen I, Claessens M, Mårild S, Lissner L, Bammann K, Intemann T, Buck C, Pigeot I, Ahrens W, Molnár D, IDEFICS Consortium. Percentile reference values for anthropometric body composition indices in European children from the IDEFICS study. Int J Obes (Lond) 2014; 38 Suppl 2: S15-25. 
352 29. Klimek-Piotrowska W, Koziej M, Hołda MK, Piątek K, Wszołek K, Tyszka A, Kmiotek E,

353 Pliczko M, Śliwińska A, Krauss K, Miszczyk M, Walocha J. Anthropometry and body

354 composition of adolescents in Cracow, Poland. PLoS One 2015; 10: e0122274. DOI:

$355 \quad$ 10.1371/journal.pone.0122274.

356 30. Statistics Canada. 2011. Canadian Health Measures Survey (CHMS) Data User Guide:

$357 \quad$ Cycle 1. Ottawa: Statistics Canada.

358 31. Statistics Canada. 2012. Canadian Health Measures Survey (CHMS) Data User Guide:

359 Cycle 2. Ottawa: Statistics Canada.

360 32. Statistics Canada. 2013. Canadian Health Measures Survey (CHMS): Instructions for

361 combining cycle 1 and cycle 2 data. Ottawa: Statistics Canada.

362 33. Cole TJ, Lobstein T. Extended international (IOTF) body mass index cut-offs for thinness, 363 overweight and obesity. Pediatr Obes 2012; 7: 284-294.

364 34. Rigby RA, Stasinopoulos DM. Smooth centile curves for skew and kurtotic data modelled 365 using the Box-Cox power exponential distribution. Stat Med 2004; 23: 3053-3076.

366 35. Cole TJ, Green PJ. Smoothing reference centile curves: the LMS method and penalized 367 likelihood. Stat Med 1992; 11: 1305-1319.

368 36. van Buuren S, Fredriks M. Worm plot: a simple diagnostic device for modelling growth 369 reference curves. Stat Med 2001; 20: 1259-1277.

370 37. R Core Team. 2016. R: A Language and Environment for Statistical Computing. Vienna, 371 Austria: R Foundation for Statistical Computing. Available at https://www.r-project.org/ $372 \quad$ (accessed June 20, 2016).

373 38. Rigby RA, Stasinopoulos DM. Using the Box-Cox t distribution in GAMLSS to model $374 \quad$ skewness and kurtosis. Stat Modelling 2006; 6: 209-229. 
375 39. Neuhauser HK, Schienkiewitz A, Schaffrath-Rosario A, Dortschy R, Kurth BM. 2011.

376 Referenzperzentile für anthropometrische Maßzahlen und Blutdruck aus der Studie zur

377 Gesundheit von Kindern und Jugendlichen in Deutschland (KiGGS) 2003-2006. Berlin:

$378 \quad$ Robert-Koch Institut.

379 40. Bowen PE, Custer PB. Reference values and age-related trends for arm muscle area, arm 380 fat area, and sum of skinfolds for United States adults. J Am Coll Nutr 1984; 3: 357-376.

381 41. Rodríguez G, Moreno LA, Blay MG, Blay VA, Fleta J, Sarría A, Bueno M, AVENAZaragoza Study Group. Body fat measurement in adolescents: comparison of skinfold thickness equations with dual-energy X-ray absorptiometry. Eur J Clin Nutr 2005; 59: 1158-1166.

42. Slaughter MH, Lohman TG, Boileau RA, Horswill CA, Stillman RJ, Van Loan MD, Bemben DA. Skinfold equations for estimation of body fatness in children and youth. Hum Biol 1988; 60: 709-723.

43. Wells JC, Fewtrell MS. Measuring body composition. Arch Dis Child 2006; 91: 612-617.

44. Wells JC, Fuller NJ, Dewit O, Fewtrell MS, Elia M, Cole TJ. Four-component model of body composition in children: density and hydration of fat-free mass and comparison with simpler models. Am J Clin Nutr 1999; 69: 904-912.

45. Freedman DS, Horlick M, Berenson GS. A comparison of the Slaughter skinfold-thickness equations and BMI in predicting body fatness and cardiovascular disease risk factor levels in children. Am J Clin Nutr 2013; 98: 1417-1424.

46. Wells JC, Williams JE, Chomtho S, Darch T, Grijalva-Eternod C, Kennedy K, Haroun D, Wilson C, Cole TJ, Fewtrell MS. Body-composition reference data for simple and reference techniques and a 4-component model: a new UK reference child. Am J Clin Nutr 
2012; 96: 1316-1326.

399

400

401

402

403

404

405

406

407

408

409

410

411

47. van der Sluis IM, de Ridder MA, Boot AM, Krenning EP, de Muinck Keizer-Schrama SM. Reference data for bone density and body composition measured with dual energy $\mathrm{x}$ ray absorptiometry in white children and young adults. Arch Dis Child 2002; 87: 341-7.

48. Kelishadi R, Mirmoghtadaee P, Najafi H, Keikha M. Systematic review on the association of abdominal obesity in children and adolescents with cardio-metabolic risk factors. $J$ Res Med Sci 2015; 20: 294-307.

49. de Onis M, Onyango A, Borghi E, Siyam A, Nishida C, Pinol A. 2009. WHO child growth standards: growth velocity based on weight, length and head circumference: methods and development. Geneva: WHO.

50. Kuhle S, Maguire B, Ata N, Hamilton D. Percentile Curves for Anthropometric Measures for Canadian Children and Youth. PLoS One 2015; 10: e0132891. DOI: 0.1371/journal.pone.0132891. 


\section{Figure 1 (on next page)}

Percentile curves for biceps skinfold thickness for male and female Canadian children and youth aged 6 to 19 years. 


\section{Male}

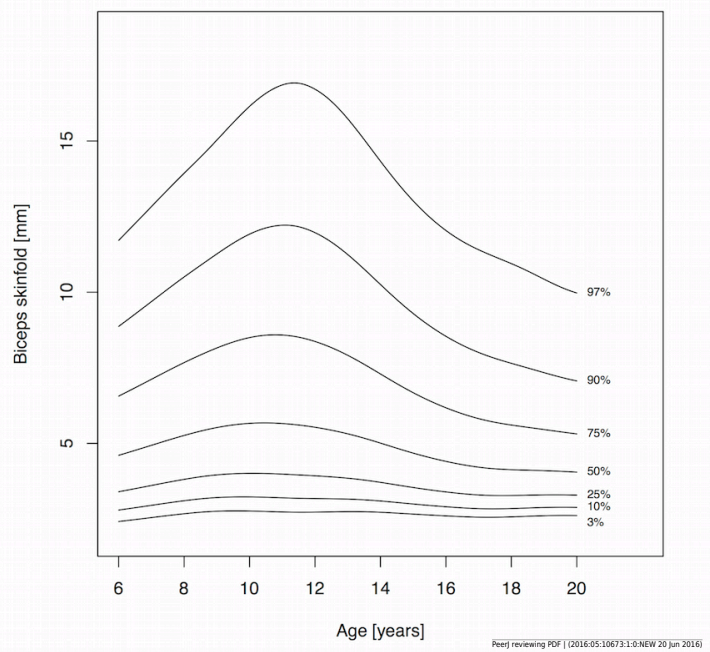

Female

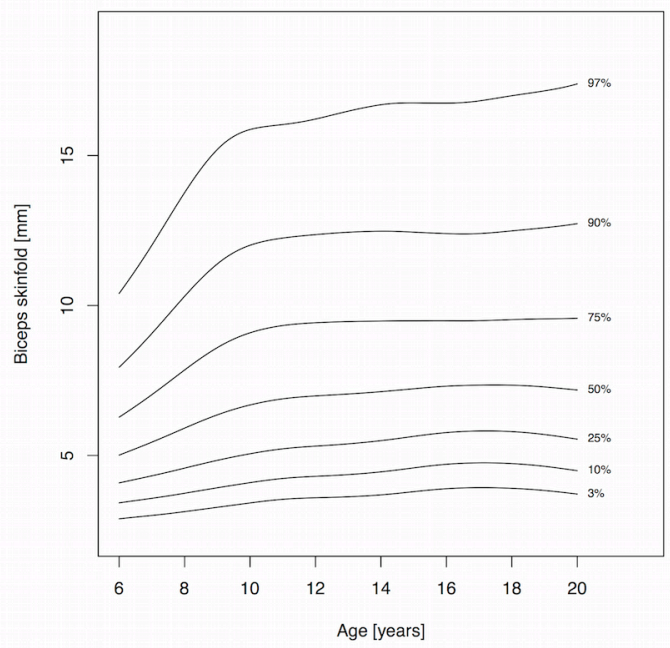


Figure 2 (on next page)

Percentile curves for triceps skinfold thickness for male and female Canadian children and youth aged 6 to 19 years. 


\section{Male}

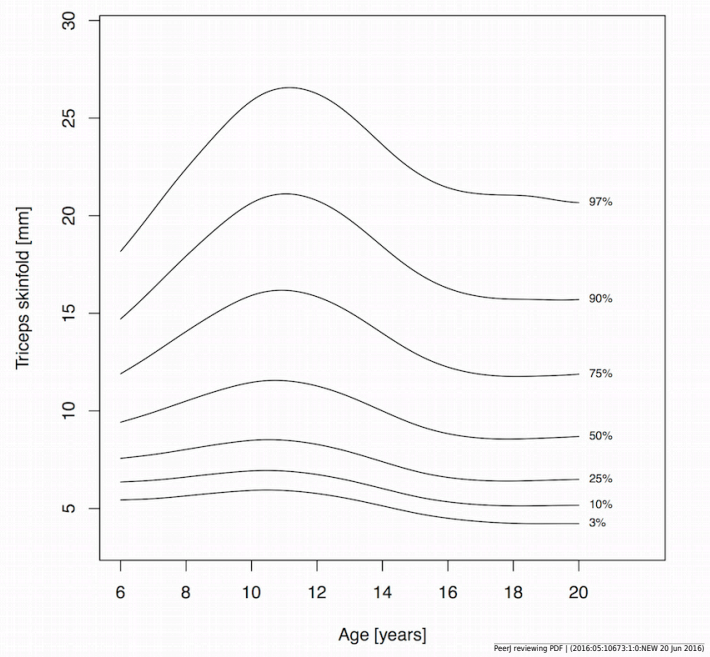

\section{Female}

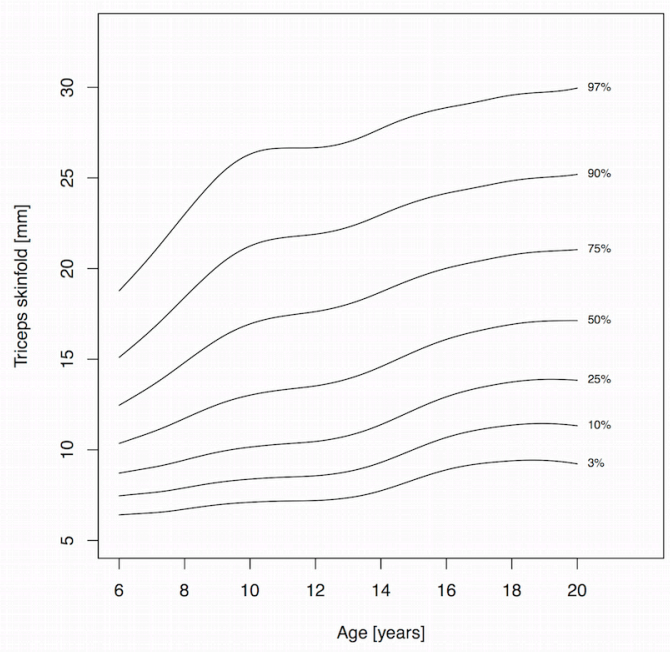




\section{Figure 3 (on next page)}

Percentile curves for subscapular skinfold thickness for male and female Canadian children and youth aged 6 to 19 years. 

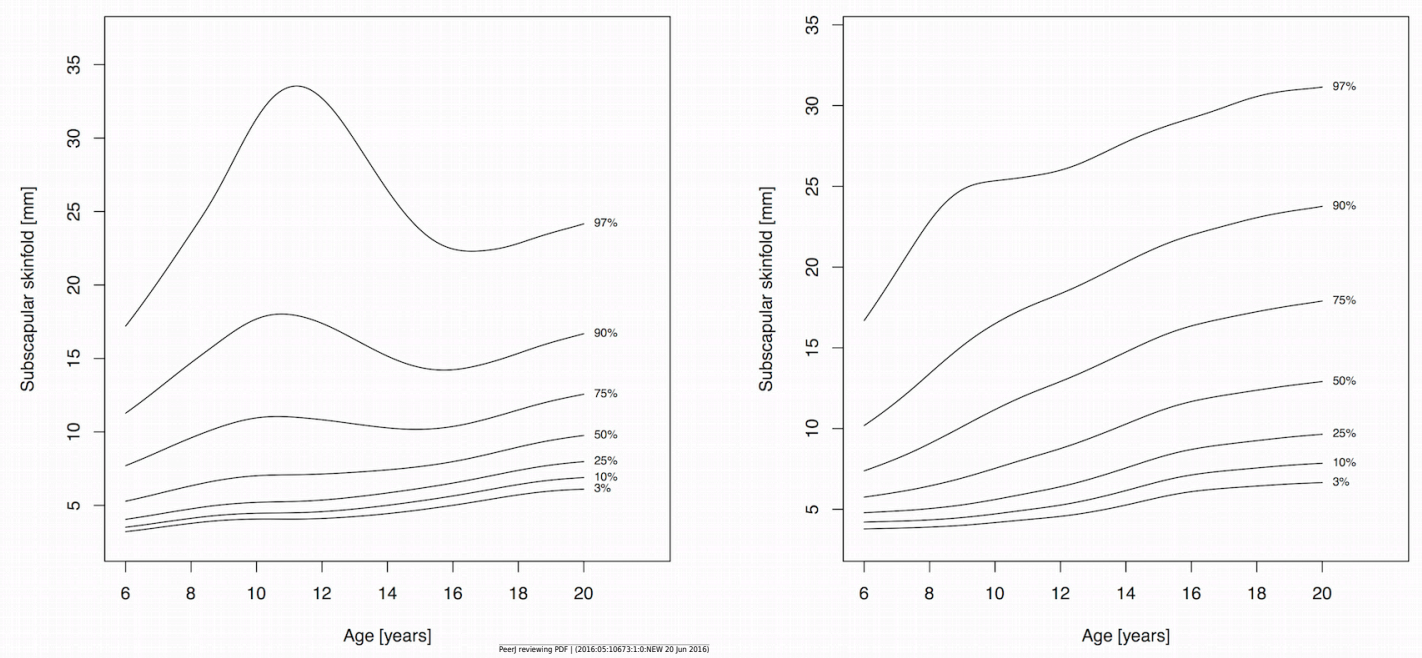
Figure 4 (on next page)

Percentile curves for suprailiac skinfold thickness for male and female Canadian children and youth aged 6 to 19 years. 

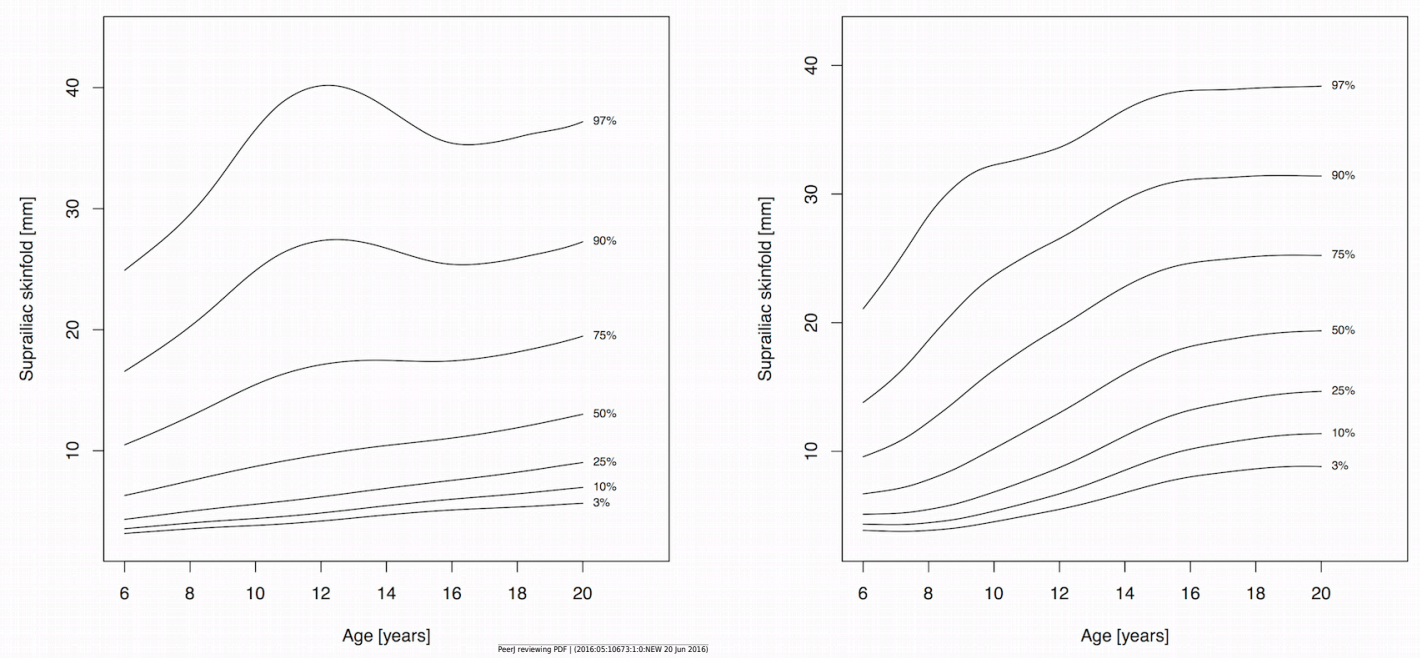
Figure $\mathbf{5}$ (on next page)

Percentile curves for medial calf skinfold thickness for male and female Canadian children and youth aged 6 to 19 years. 
PeerJ

\section{Male}

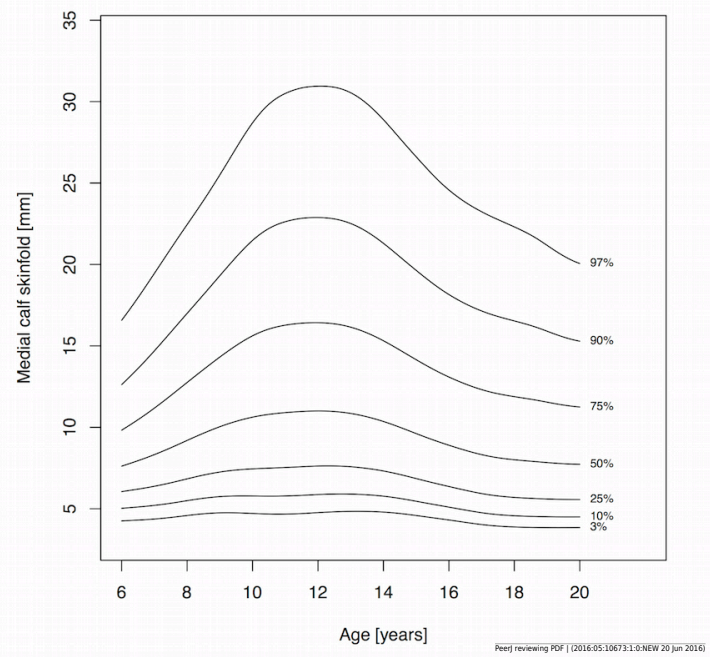

\section{Female}

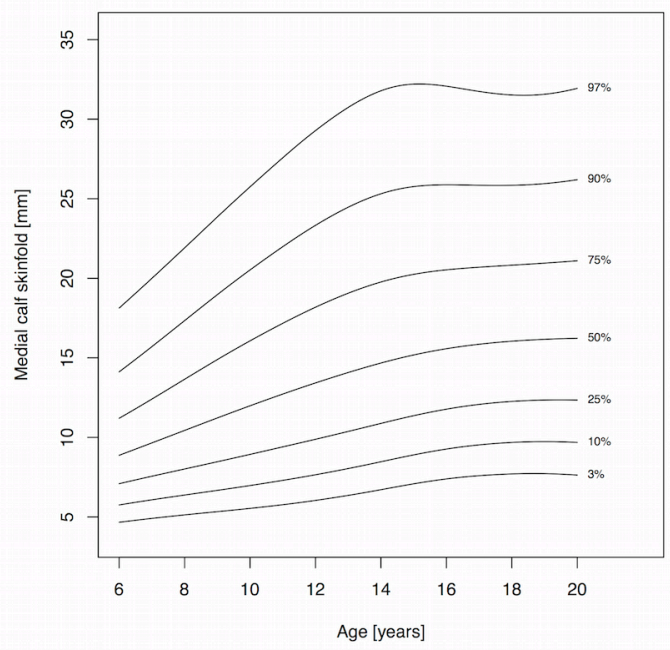




\section{Table $\mathbf{1}$ (on next page)}

Characteristics of 4115 Canadian children and youth aged 6 to 19 years in the Canadian Health Measures Survey cycles 1 and 2.

${ }^{\mathrm{E}}$ Coefficient of variation between $16.6 \%$ and $33.3 \%$; interpret with caution as per Statistics Canada sampling variability reporting guidelines. 
1

Prevalence [\%]

Sex

Male

51.5

Female

48.5

Region of Canada

Atlantic Canada

$6.7^{\mathrm{E}}$

Québec

22.5

Ontario

40.9

Prairies

17.8

British Columbia

12.1

Racial origin

White

83.3

Black

$6.3^{\mathrm{E}}$

Asian

8.1

Other

$2.3^{\mathrm{E}}$

Weight status

Underweight

7.2

Normal weight

66.2

Overweight

17.0

Obese

9.6

Household education

Secondary school or less

14.1

College

50.2

University

35.7

Household income

$\$ 30,000$ or less

13.6

$\$ 30,001-\$ 60,000$

23.3

$\$ 60,001-\$ 80,000$

19.4

$\$ 80,001-\$ 100,000$

16.6

$>\$ 100,000$

27.1

2 
Table 2 (on next page)

Sample size, median, and interquartile range for biceps, triceps, subscapular, suprailiac, and medial calf skinfold thickness [mm] for Canadian children and youth aged 6 to 19 years.

Abbreviations: IQR Interquartile range. 


\begin{tabular}{|c|c|c|c|c|c|c|c|c|c|c|c|c|}
\hline \multirow[b]{2}{*}{ Sex } & \multirow[b]{2}{*}{$\begin{array}{l}\text { Age } \\
\text { [years] }\end{array}$} & \multirow[b]{2}{*}{ n } & \multicolumn{2}{|l|}{ Biceps } & \multicolumn{2}{|l|}{ Triceps } & \multicolumn{2}{|c|}{ Subscapular } & \multicolumn{2}{|c|}{ Suprailiac } & \multicolumn{2}{|c|}{ Medial calf } \\
\hline & & & $\begin{array}{l}\text { Media } \\
\text { n }\end{array}$ & $\begin{array}{l}\text { IQ } \\
\text { R }\end{array}$ & $\begin{array}{l}\text { Media } \\
\text { n }\end{array}$ & $\begin{array}{l}\text { IQ } \\
\text { R }\end{array}$ & $\begin{array}{l}\text { Media } \\
\text { n }\end{array}$ & $\begin{array}{l}\text { IQ } \\
\text { R }\end{array}$ & $\begin{array}{l}\text { Media } \\
\text { n }\end{array}$ & $\begin{array}{l}\text { IQ } \\
\text { R }\end{array}$ & $\begin{array}{l}\text { Media } \\
\text { n }\end{array}$ & \begin{tabular}{|l|} 
IQ \\
R
\end{tabular} \\
\hline $\begin{array}{l}\text { Femal } \\
\mathrm{e}\end{array}$ & 6 & $\begin{array}{r}15 \\
4 \\
\end{array}$ & 5.0 & 1.6 & 10.5 & 3.1 & 5.4 & 2.3 & 5.9 & 2.7 & 8.7 & 3.3 \\
\hline & 7 & $\begin{array}{r}14 \\
0 \\
\end{array}$ & 5.1 & 2.9 & 11.0 & 5.0 & 5.6 & 2.7 & 6.8 & 5.1 & 10.0 & 4.3 \\
\hline & 8 & $\begin{array}{r}16 \\
4\end{array}$ & 6.4 & 4.3 & 11.9 & 6.8 & 6.6 & 6.0 & 8.1 & 7.7 & 10.5 & 7.0 \\
\hline & 9 & $\begin{array}{r}17 \\
4 \\
\end{array}$ & 7.3 & 4.4 & 13.1 & 7.7 & 8.1 & 8.4 & 11.2 & 11.0 & 12.1 & 7.3 \\
\hline & 10 & $\begin{array}{r}19 \\
3\end{array}$ & 6.9 & 3.4 & 13.1 & 6.4 & 8.3 & 6.4 & 10.6 & 10.0 & 12.7 & 7.3 \\
\hline & 11 & $\begin{array}{r}20 \\
9\end{array}$ & 7.2 & 4.1 & 12.4 & 6.3 & 8.5 & 4.9 & 11.9 & 10.3 & 13.2 & 7.0 \\
\hline & 12 & $\begin{array}{r}12 \\
7\end{array}$ & 7.5 & 4.1 & 13.9 & 6.4 & 8.9 & 7.7 & 13.6 & 11.9 & 12.7 & 9.4 \\
\hline & 13 & $\begin{array}{r}13 \\
1 \\
\end{array}$ & 7.3 & 3.1 & 14.0 & 7.9 & 9.1 & 8.3 & 16.1 & 14.7 & 13.6 & 10.0 \\
\hline & 14 & $\begin{array}{r}11 \\
6 \\
\end{array}$ & 7.8 & 4.1 & 16.1 & 8.8 & 12.0 & 7.4 & 17.3 & 12.3 & 15.9 & 9.4 \\
\hline & 15 & $\begin{array}{r}11 \\
8 \\
\end{array}$ & 7.4 & 4.3 & 16.3 & 8.0 & 11.1 & 8.5 & 17.7 & 14.4 & 15.0 & 9.5 \\
\hline & 16 & $\begin{array}{r}10 \\
9\end{array}$ & 7.0 & 1.8 & 17.0 & 4.5 & 10.6 & 5.4 & 18.9 & 8.9 & 15.9 & 7.1 \\
\hline & 17 & $\begin{array}{r}11 \\
1 \\
\end{array}$ & 7.5 & 3.5 & 16.8 & 6.1 & 12.9 & 7.7 & 21.1 & 12.3 & 17.0 & 8.7 \\
\hline & 18 & $\begin{array}{r}10 \\
4 \\
\end{array}$ & 7.4 & 2.7 & 17.3 & 5.1 & 11.8 & 8.3 & 19.4 & 10.4 & 14.8 & 7.0 \\
\hline & 19 & 92 & 7.2 & 4.2 & 17.5 & 7.9 & 11.8 & 6.0 & 19.8 & 11.2 & 16.9 & 8.1 \\
\hline Male & 6 & $\begin{array}{r}15 \\
2 \\
\end{array}$ & 4.3 & 2.6 & 9.0 & 3.6 & 5.0 & 2.4 & 5.3 & 3.4 & 7.7 & 4.2 \\
\hline & 7 & $\begin{array}{r}16 \\
3\end{array}$ & 5.0 & 3.6 & 10.2 & 7.0 & 5.3 & 5.3 & 5.6 & 8.1 & 9.1 & 7.0 \\
\hline & 8 & $\begin{array}{r}16 \\
7\end{array}$ & 5.2 & 3.6 & 10.4 & 5.9 & 6.1 & 3.8 & 7.2 & 8.5 & 8.2 & 5.6 \\
\hline & 9 & $\begin{array}{r}16 \\
4 \\
\end{array}$ & 6.0 & 4.8 & 11.1 & 7.5 & 6.2 & 5.3 & 7.0 & 10.3 & 9.8 & 9.1 \\
\hline & 10 & $\begin{array}{r}20 \\
4\end{array}$ & 6.8 & 5.8 & 12.8 & 8.8 & 7.5 & 9.4 & 9.6 & 15.2 & 12.4 & 11.5 \\
\hline & 11 & $\begin{array}{r}18 \\
5 \\
\end{array}$ & 5.5 & 4.5 & 11.1 & 8.8 & 6.8 & 4.8 & 9.9 & 9.6 & 10.3 & 9.1 \\
\hline & 12 & $\begin{array}{r}14 \\
8 \\
\end{array}$ & 5.7 & 4.4 & 12.1 & 8.4 & 6.8 & 5.0 & 7.9 & 13.4 & 10.6 & 9.3 \\
\hline & 13 & $\begin{array}{r}14 \\
1 \\
\end{array}$ & 5.3 & 4.6 & 10.8 & 8.3 & 7.0 & 5.7 & 9.7 & 10.4 & 10.5 & 9.8 \\
\hline & 14 & $\begin{array}{r}13 \\
6 \\
\end{array}$ & 4.4 & 2.3 & 9.0 & 3.1 & 7.3 & 2.4 & 9.8 & 5.5 & 9.5 & 5.7 \\
\hline & 15 & $\begin{array}{r}11 \\
9\end{array}$ & 4.4 & 2.2 & 8.1 & 5.0 & 7.2 & 2.3 & 9.2 & 5.2 & 7.9 & 5.7 \\
\hline & 16 & $\begin{array}{r}13 \\
0\end{array}$ & 4.0 & 1.8 & 8.2 & 4.9 & 7.8 & 2.9 & 10.2 & 6.7 & 7.9 & 5.5 \\
\hline & 17 & 11 & 3.9 & 1.9 & 8.4 & 4.6 & 8.5 & 3.8 & 10.2 & 11.5 & 8.4 & 5.3 \\
\hline
\end{tabular}




\begin{tabular}{|r|r|r|r|r|r|r|r|r|r|r|r|r|}
\hline & & 4 & & & & & & & & & & \\
\hline & 18 & 91 & 4.2 & 3.3 & 8.8 & 5.7 & 9.4 & 4.6 & 13.2 & 12.9 & 7.4 & 8.5 \\
\hline
\end{tabular}

2 


\section{Table 3(on next page)}

Parameter values $(\mu, \sigma, \nu, \tau)$ and percentiles of biceps skinfold thickness [mm] by age and sex for Canadian children and youth aged 6 to 19 years. 
1

\begin{tabular}{|c|c|c|c|c|c|c|c|c|c|c|c|c|}
\hline Sex & Age [years] & $\mu$ & $\sigma$ & $v$ & $\tau$ & $3^{\text {rd }}$ & $10^{\text {th }}$ & $25^{\text {th }}$ & $50^{\text {th }}$ & $75^{\text {th }}$ & $90^{\text {th }}$ & $97^{\text {th }}$ \\
\hline \multirow[t]{28}{*}{ Female } & 6 & 5.0119 & 0.3284 & -0.4418 & 1.8070 & 2.89 & 3.42 & 4.08 & 5.01 & 6.28 & 7.94 & 10.40 \\
\hline & 6.5 & 5.2250 & 0.3435 & -0.4262 & 1.9030 & 2.94 & 3.50 & 4.20 & 5.22 & 6.64 & 8.49 & 11.18 \\
\hline & 7 & 5.4445 & 0.3591 & -0.4114 & 2.0020 & 3.00 & 3.57 & 4.32 & 5.44 & 7.03 & 9.07 & 12.01 \\
\hline & 7.5 & 5.6746 & 0.3742 & -0.3977 & 2.1006 & 3.06 & 3.65 & 4.45 & 5.67 & 7.44 & 9.69 & 12.89 \\
\hline & 8 & 5.9118 & 0.3874 & -0.3847 & 2.1941 & 3.13 & 3.74 & 4.58 & 5.91 & 7.85 & 10.31 & 13.76 \\
\hline & 8.5 & 6.1425 & 0.3979 & -0.3716 & 2.2785 & 3.20 & 3.83 & 4.71 & 6.14 & 8.25 & 10.89 & 14.55 \\
\hline & 9 & 6.3538 & 0.4052 & -0.3583 & 2.3518 & 3.27 & 3.92 & 4.84 & 6.35 & 8.60 & 11.39 & 15.20 \\
\hline & 9.5 & 6.5358 & 0.4087 & -0.3444 & 2.4148 & 3.34 & 4.01 & 4.95 & 6.54 & 8.88 & 11.76 & 15.64 \\
\hline & 10 & 6.6843 & 0.4085 & -0.3318 & 2.4636 & 3.42 & 4.09 & 5.06 & 6.68 & 9.09 & 12.01 & 15.87 \\
\hline & 10.5 & 6.8017 & 0.4061 & -0.3223 & 2.4902 & 3.48 & 4.17 & 5.15 & 6.80 & 9.24 & 12.16 & 15.97 \\
\hline & 11 & 6.8887 & 0.4035 & -0.3159 & 2.4912 & 3.54 & 4.23 & 5.22 & 6.89 & 9.33 & 12.25 & 16.03 \\
\hline & 11.5 & 6.9462 & 0.4021 & -0.3131 & 2.4669 & 3.57 & 4.28 & 5.27 & 6.95 & 9.39 & 12.31 & 16.11 \\
\hline & 12 & 6.9848 & 0.4016 & -0.3135 & 2.4202 & 3.59 & 4.30 & 5.31 & 6.98 & 9.43 & 12.36 & 16.22 \\
\hline & 12.5 & 7.0172 & 0.4014 & -0.3167 & 2.3565 & 3.60 & 4.33 & 5.35 & 7.02 & 9.45 & 12.41 & 16.35 \\
\hline & 13 & 7.0502 & 0.4005 & -0.3224 & 2.2830 & 3.62 & 4.36 & 5.39 & 7.05 & 9.46 & 12.44 & 16.48 \\
\hline & 13.5 & 7.0857 & 0.3986 & -0.3305 & 2.2067 & 3.65 & 4.40 & 5.44 & 7.09 & 9.47 & 12.47 & 16.60 \\
\hline & 14 & 7.1271 & 0.3956 & -0.3402 & 2.1308 & 3.69 & 4.45 & 5.49 & 7.13 & 9.48 & 12.48 & 16.69 \\
\hline & 14.5 & 7.1747 & 0.3910 & -0.3507 & 2.0577 & 3.74 & 4.52 & 5.56 & 7.17 & 9.49 & 12.47 & 16.75 \\
\hline & 15 & 7.2244 & 0.3855 & -0.3612 & 1.9904 & 3.79 & 4.59 & 5.64 & 7.22 & 9.49 & 12.45 & 16.76 \\
\hline & 15.5 & 7.2719 & 0.3802 & -0.3707 & 1.9315 & 3.85 & 4.65 & 5.71 & 7.27 & 9.49 & 12.42 & 16.75 \\
\hline & 16 & 7.3094 & 0.3760 & -0.3782 & 1.8827 & 3.89 & 4.71 & 5.76 & 7.31 & 9.49 & 12.40 & 16.75 \\
\hline & 16.5 & 7.3323 & 0.3737 & -0.3 & 1.8459 & 3.92 & 4.74 & 5.80 & 7.33 & 9.49 & 12.39 & 16.77 \\
\hline & 17 & 7.3447 & 0.3733 & -0.3873 & 1.8256 & 3.93 & 4.75 & 5.82 & 7.34 & 9.49 & 12.40 & 16.82 \\
\hline & 17.5 & 7.3491 & 0.3747 & -0.3893 & 1.8254 & 3.92 & 4.75 & 5.81 & 7.35 & 9.51 & 12.44 & 16.91 \\
\hline & 18 & 7.3424 & 0.3774 & -0.3895 & 1.8451 & 3.90 & 4.73 & 5.80 & 7.34 & 9.53 & 12.49 & 16.99 \\
\hline & 18.5 & 7.3213 & 0.3812 & -0.3886 & 1.8817 & 3.88 & 4.69 & 5.76 & 7.32 & 9.55 & 12.54 & 17.08 \\
\hline & 19 & 7.2844 & 0.3863 & -0.3872 & 1.9314 & 3.83 & 4.64 & 5.70 & 7.28 & 9.56 & 12.59 & 17.16 \\
\hline & 19.5 & 7.2355 & 0.3926 & -0.3849 & 1.9906 & 3.78 & 4.57 & 5.62 & 7.24 & 9.56 & 12.65 & 17.26 \\
\hline \multirow[t]{27}{*}{ Male } & 6 & 4.6047 & 0.4244 & -0.4739 & 3.4627 & 2.42 & 2.79 & 3.40 & 4.60 & 6.56 & 8.87 & 11.71 \\
\hline & 6.5 & 4.7687 & 0.4305 & -0.4661 & 3.5181 & 2.48 & 2.87 & 3.50 & 4.77 & 6.84 & 9.27 & 12.27 \\
\hline & 7 & 4.9358 & 0.4363 & -0.4586 & 3.5741 & 2.55 & 2.95 & 3.61 & 4.94 & 7.12 & 9.69 & 12.83 \\
\hline & 7.5 & 5.1030 & 0.4417 & -0.4516 & 3.6290 & 2.61 & 3.03 & 3.71 & 5.10 & 7.40 & 10.10 & 13.39 \\
\hline & 8 & 5.2617 & 0.4471 & -0.4447 & 3.6814 & 2.67 & 3.10 & 3.81 & 5.26 & 7.67 & 10.50 & 13.93 \\
\hline & 8.5 & 5.4051 & 0.4527 & -0.4387 & 3.7288 & 2.72 & 3.17 & 3.90 & 5.41 & 7.92 & 10.89 & 14.47 \\
\hline & 9 & 5.5233 & 0.4601 & -0.4341 & 3.7636 & 2.76 & 3.21 & 3.96 & 5.52 & 8.16 & 11.26 & 15.03 \\
\hline & 9.5 & 5.6104 & 0.4689 & & 3.7813 & 2.77 & 3.23 & 4.00 & 5.61 & 8.35 & 11.62 & 15.61 \\
\hline & 10 & 5.6625 & 0.4775 & -0.4333 & 3.7815 & 2.76 & 3.23 & 4.01 & 5.66 & 8.50 & 11.92 & 16.15 \\
\hline & 10.5 & 5.6775 & 0.4843 & -0.4396 & 3.7661 & 2.75 & 3.22 & 4.00 & 5.68 & 8.58 & 12.13 & 16.58 \\
\hline & 11 & 5.6570 & 0.4881 & -0.4520 & 3.7424 & 2.73 & 3.20 & 3.98 & 5.66 & 8.58 & 12.21 & 16.85 \\
\hline & 11.5 & 5.6073 & 0.4872 & -0.4719 & 3.7241 & 2.72 & 3.18 & 3.96 & 5.61 & 8.51 & 12.16 & 16.91 \\
\hline & 12 & 5.5336 & 0.4807 & -0.5000 & 3.7181 & 2.73 & 3.18 & 3.93 & 5.53 & 8.37 & 11.97 & 16.71 \\
\hline & 12.5 & 5.4364 & 0.4702 & -0.5358 & 3.7237 & 2.73 & 3.17 & 3.89 & 5.44 & 8.17 & 11.66 & 16.31 \\
\hline & 13 & 5.3165 & 0.4566 & -0.5778 & 3.7347 & 2.74 & 3.16 & 3.85 & 5.32 & 7.91 & 11.24 & 15.74 \\
\hline & 13.5 & 5.1723 & 0.4417 & -0.6236 & 3.7404 & 2.74 & 3.13 & 3.79 & 5.17 & 7.62 & 10.76 & 15.05 \\
\hline & 14 & 5.0096 & 0.4270 & -0.6718 & 3.7345 & 2.72 & 3.09 & 3.71 & 5.01 & 7.30 & 10.25 & 14.33 \\
\hline & 14.5 & 4.8405 & 0.4130 & -0.7220 & 3.7191 & 2.69 & 3.05 & 3.63 & 4.84 & 6.98 & 9.76 & 13.64 \\
\hline & 15 & 4.6786 & 0.4001 & -0.7736 & 3.6995 & 2.66 & 3.00 & 3.54 & 4.68 & 6.68 & 9.30 & 13.02 \\
\hline & 15.5 & 4.5328 & 0.3883 & -0.8253 & 3.6730 & 2.63 & 2.95 & 3.46 & 4.53 & 6.41 & 8.89 & 12.49 \\
\hline & 16 & 4.4054 & 0.3778 & -0.8752 & 3.6340 & 2.60 & 2.90 & 3.39 & 4.41 & 6.18 & 8.54 & 12.04 \\
\hline & 16.5 & 4.2974 & 0.3687 & -0.9217 & 3.5769 & 2.58 & 2.87 & 3.34 & 4.30 & 5.98 & 8.25 & 11.68 \\
\hline & 17 & 4.2135 & 0.3604 & -0.9645 & 3.5010 & 2.56 & 2.84 & 3.29 & 4.21 & 5.82 & 8.01 & 11.40 \\
\hline & 17.5 & 4.1592 & 0.3521 & -1.0039 & 3.4112 & 2.56 & 2.84 & 3.28 & 4.16 & 5.70 & 7.81 & 11.17 \\
\hline & 18 & 4.1304 & 0.3435 & -1.0395 & 3.3156 & 2.57 & 2.85 & 3.28 & 4.13 & 5.61 & 7.65 & 10.95 \\
\hline & 18.5 & 4.1142 & 0.3347 & -1.0703 & 3.2195 & 2.59 & 2.86 & 3.29 & 4.11 & 5.53 & 7.49 & 10.70 \\
\hline & 19 & 4.0987 & 0.3261 & -1.0957 & 3.1256 & 2.61 & 2.88 & 3.30 & 4.10 & 5.46 & 7.34 & 10.43 \\
\hline
\end{tabular}




\section{Table 4(on next page)}

Parameter values $(\mu, \sigma, \nu, \tau)$ and percentiles of triceps skinfold thickness [mm] by age and sex for Canadian children and youth aged 6 to 19 years. 


\begin{tabular}{|c|c|c|c|c|c|c|c|c|c|c|c|c|}
\hline Sex & Age [years] & $\mu$ & $\sigma$ & $v$ & $\tau$ & $3^{\text {rd }}$ & $10^{\text {th }}$ & $25^{\text {th }}$ & $50^{\text {th }}$ & $7^{\text {th }}$ & 90 $^{\text {th }}$ & $97^{\text {th }}$ \\
\hline \multirow[t]{28}{*}{ Female } & 6 & 10.3527 & 0.2772 & -0.4045 & 1.7405 & 6.41 & 7.46 & 8.71 & 10.35 & 12.46 & 15.1 & 18.77 \\
\hline & 6.5 & 10.6593 & 0.2898 & -0.3782 & 1.8402 & 6.47 & 7.55 & 8.87 & 10.66 & 12.99 & 15.85 & 19.74 \\
\hline & 7 & 10.9767 & 0.3028 & -0.3527 & 1.9457 & 6.52 & 7.64 & 9.03 & 10.98 & 13.54 & 16.64 & 20.77 \\
\hline & 7.5 & 11.3334 & 0.3151 & -0.3301 & 2.0578 & 6.61 & 7.75 & 9.21 & 11.33 & 14.16 & 17.50 & 21.87 \\
\hline & 8 & 11.7320 & 0.3256 & -0.3103 & 2.1734 & 6.73 & 7.90 & 9.44 & 11.73 & 14.82 & 18.41 & 22.99 \\
\hline & 8.5 & 12.1291 & 0.3348 & -0.2919 & 2.2869 & 6.86 & 8.06 & 9.66 & 12.13 & 15.47 & 19.29 & 24.06 \\
\hline & 9 & 12.4911 & 0.3431 & -0.2737 & 2.3917 & 6.97 & 8.20 & 9.87 & 12.49 & 16.07 & 20.11 & 25.04 \\
\hline & 9.5 & 12.7889 & 0.3498 & -0.2538 & 2.4833 & 7.05 & 8.31 & 10.03 & 12.79 & 16.57 & 20.77 & 25.81 \\
\hline & 10 & 13.0158 & 0.3544 & -0.2315 & 2.5568 & 7.11 & 8.38 & 10.15 & 13.02 & 16.94 & 21.24 & 26.31 \\
\hline & 10.5 & 13.1858 & 0.3567 & -0.2062 & 2.6095 & 7.15 & 8.44 & 10.25 & 13.19 & 17.20 & 21.54 & 26.57 \\
\hline & 11 & 13.3113 & 0.3576 & -0.1770 & 2.6435 & 7.17 & 8.49 & 10.32 & 13.31 & 17.38 & 21.70 & 26.65 \\
\hline & 11.5 & 13.4136 & 0.3580 & -0.1454 & 2.6597 & 7.19 & 8.52 & 10.38 & 13.41 & 17.50 & 21.80 & 26.65 \\
\hline & 12 & 13.5272 & 0.3579 & -0.1136 & 2.6561 & 7.20 & 8.57 & 10.46 & 13.53 & 17.63 & 21.90 & 26.67 \\
\hline & 12.5 & 13.6910 & 0.3569 & -0.0836 & 2.6324 & 7.26 & 8.66 & 10.59 & 13.69 & 17.80 & 22.05 & 26.77 \\
\hline & 13 & 13.9211 & 0.3550 & -0.0573 & 2.5904 & 7.36 & 8.80 & 10.79 & 13.92 & 18.04 & 22.29 & 26.99 \\
\hline & 13.5 & 14.2201 & 0.3518 & -0.0366 & 2.5346 & 7.52 & 9.02 & 11.05 & 14.22 & 18.34 & 22.60 & 27.32 \\
\hline & 14 & 14.5871 & 0.3466 & -0.0219 & 2.4691 & 7.74 & 9.30 & 11.39 & 14.59 & 18.71 & 22.97 & 27.72 \\
\hline & 14.5 & 14.9915 & 0.3394 & -0.0108 & 2.3963 & 8.03 & 9.65 & 11.78 & 14.99 & 19.09 & 23.34 & 28.10 \\
\hline & 15 & 15.3946 & 0.3311 & -0.0005 & 2.3207 & 8.34 & 10.02 & 12.19 & 15.39 & 19.44 & 23.66 & 28.42 \\
\hline & 15.5 & 15.7700 & 0.3229 & 0.0106 & 2.2476 & 8.64 & 10.37 & 12.58 & 15.77 & 19.75 & 23.93 & 28.68 \\
\hline & 16 & 16.0934 & 0.3159 & 0.0236 & 2.1810 & 8.90 & 10.68 & 12.92 & 16.09 & 20.02 & 24.15 & 28.88 \\
\hline & 16.5 & 16.3567 & 0.3106 & 0.0384 & 2.1230 & 9.09 & 10.93 & 13.2 & 16.36 & 20.23 & 24.33 & 29.04 \\
\hline & 17 & 16.5739 & 0.3074 & 0.0549 & 2.0757 & 9.23 & 11.11 & 13.42 & 16.57 & 20.42 & 24.51 & 29.22 \\
\hline & 17.5 & 16.7618 & 0.3058 & 0.0727 & 2.0406 & 9.33 & 11.25 & 13.6 & 16.76 & 20.60 & 24.69 & 29.41 \\
\hline & 18 & 16.9205 & 0.3048 & 0.0917 & 2.0177 & 9.39 & 11.36 & 13.74 & 16.92 & 20.75 & 24.85 & 29.57 \\
\hline & 18.5 & 17.0364 & 0.3044 & 0.1114 & 2.0040 & 9.43 & 11.43 & 13.84 & 17.04 & 20.87 & 24.96 & 29.67 \\
\hline & 19 & 17.1018 & 0.3049 & 0.1318 & 1.9946 & 9.42 & 11.45 & 13.89 & 17.10 & 20.95 & 25.03 & 29.73 \\
\hline & 19.5 & 17.1266 & 0.3072 & 0.1525 & 1.9862 & 9.35 & 11.41 & 13.88 & 17.13 & 20.99 & 25.10 & 29.81 \\
\hline \multirow[t]{27}{*}{ Male } & 6 & 9.4200 & 0.3219 & -0.2987 & 2.2897 & 5.44 & 6.36 & 7.57 & 9.42 & 11.90 & 14.71 & 18.18 \\
\hline & 6.5 & 9.6662 & 0.3372 & -0.2968 & 2.4350 & 5.47 & 6.40 & 7.66 & 9.67 & 12.41 & 15.47 & 19.20 \\
\hline & 7 & 9.9299 & 0.3520 & -0.2951 & 2.5915 & 5.51 & 6.45 & 7.77 & 9.93 & 12.94 & 16.29 & 20.29 \\
\hline & 7.5 & 10.2151 & 0.3651 & -0.2933 & 2.7567 & 5.57 & 6.52 & 7.89 & 10.22 & 13.51 & 17.12 & 21.37 \\
\hline & 8 & 10.5047 & 0.3761 & -0.2908 & 2.9221 & 5.65 & 6.61 & 8.03 & 10.50 & 14.07 & 17.93 & 22.41 \\
\hline & 8.5 & 10.7871 & 0.3856 & -0.2881 & 3.0790 & 5.73 & 6.71 & 8.16 & 10.79 & 14.60 & 18.71 & 23.38 \\
\hline & 9 & 11.0506 & 0.3943 & -0.2861 & 3.2188 & 5.81 & 6.79 & 8.29 & 11.05 & 15.11 & 19.45 & 24.32 \\
\hline & 9.5 & 11.2822 & 0.4020 & -0.2859 & 3.3368 & 5.88 & 6.87 & 8.41 & 11.28 & 15.56 & 20.11 & 25.18 \\
\hline & 10 & 11.4608 & 0.4081 & -0.2879 & 3.4329 & 5.93 & 6.93 & 8.49 & 11.46 & 15.91 & 20.65 & 25.88 \\
\hline & 10.5 & 11.5533 & 0.4127 & -0.2912 & 3.5032 & 5.95 & 6.95 & 8.53 & 11.55 & 16.13 & 20.99 & 26.35 \\
\hline & 11 & 11.5478 & 0.4160 & -0.2954 & 3.5419 & 5.92 & 6.92 & 8.50 & 11.55 & 16.18 & 21.12 & 26.55 \\
\hline & 11.5 & 11.4527 & 0.4182 & -0.3004 & 3.5484 & 5.86 & 6.85 & 8.42 & 11.45 & 16.08 & 21.04 & 26.51 \\
\hline & 12 & 11.2775 & 0.4193 & -0.3065 & 3.5262 & 5.77 & 6.74 & 8.29 & 11.28 & 15.85 & 20.77 & 26.25 \\
\hline & 12.5 & 11.0300 & 0.4197 & -0.3135 & 3.4821 & 5.64 & 6.60 & 8.11 & 11.03 & 15.50 & 20.35 & 25.79 \\
\hline & 13 & 10.7229 & 0.4191 & -0.3213 & 3.4194 & 5.49 & 6.43 & 7.90 & 10.72 & 15.05 & 19.79 & 25.16 \\
\hline & 13.5 & 10.3697 & 0.4183 & -0.3293 & 3.3374 & 5.32 & 6.23 & 7.65 & 10.37 & 14.53 & 19.13 & 24.42 \\
\hline & 14 & 9.9979 & 0.4173 & -0.3373 & 3.2383 & 5.14 & 6.02 & 7.40 & 10.00 & 13.98 & 18.43 & 23.64 \\
\hline & 14.5 & 9.6331 & 0.4169 & -0.3444 & 3.1272 & 4.95 & 5.82 & 7.15 & 9.63 & 13.44 & 17.75 & 22.89 \\
\hline & 15 & 9.3037 & 0.4173 & -0.3498 & 3.0095 & 4.77 & 5.62 & 6.92 & 9.30 & 12.95 & 17.15 & 22.27 \\
\hline & 15.5 & 9.0358 & 0.4179 & -0.3528 & 2.8902 & 4.62 & 5.47 & 6.73 & 9.04 & 12.55 & 16.66 & 21.78 \\
\hline & 16 & 8.8355 & 0.4189 & -0.3524 & 2.7730 & 4.50 & 5.34 & 6.59 & 8.84 & 12.24 & 16.28 & 21.44 \\
\hline & 16.5 & 8.6954 & 0.4204 & -0.3477 & 2.6613 & 4.40 & 5.25 & 6.50 & 8.70 & 12.02 & 16.02 & 21.23 \\
\hline & 17 & 8.6080 & 0.4222 & -0.3389 & 2.5605 & 4.33 & 5.19 & 6.44 & 8.61 & 11.88 & 15.86 & 21.12 \\
\hline & 17.5 & 8.5657 & 0.4241 & -0.3264 & 2.4764 & 4.28 & 5.15 & 6.41 & 8.57 & 11.80 & 15.76 & 21.07 \\
\hline & 18 & 8.5609 & 0.4257 & -0.3112 & 2.4147 & 4.24 & 5.13 & 6.41 & 8.56 & 11.77 & 15.73 & 21.05 \\
\hline & 18.5 & 8.5809 & 0.4262 & -0.2939 & 2.3794 & 4.23 & 5.14 & 6.42 & 8.58 & 11.78 & 15.71 & 21.00 \\
\hline & 19 & 8.6121 & 0.4256 & -0.2749 & 2.3676 & 4.23 & 5.15 & 6.45 & 8.61 & 11.80 & 15.69 & 20.89 \\
\hline
\end{tabular}




\section{Table 5 (on next page)}

Parameter values $(\mu, \sigma, \nu, \tau)$ and percentiles of subscapular skinfold thickness [mm] by age and sex for Canadian children and youth aged 6 to 19 years. 
1

\begin{tabular}{|c|c|c|c|c|c|c|c|c|c|c|c|c|}
\hline Sex & Age [years] & $\mu$ & $\sigma$ & $v$ & $\tau$ & $3^{\text {rd }}$ & $10^{\text {th }}$ & $25^{\text {th }}$ & $50^{\text {th }}$ & $75^{\text {th }}$ & $90^{\text {th }}$ & $97^{\text {th }}$ \\
\hline \multirow[t]{28}{*}{ Female } & 6 & 5.7916 & 0.3158 & -1.4955 & 2.0865 & 3.79 & 4.21 & 4.79 & 5.75 & 7.38 & 10.19 & 16.69 \\
\hline & 6.5 & 5.9375 & 0.3313 & -1.4087 & 2.2978 & 3.81 & 4.24 & 4.84 & 5.90 & 7.75 & 10.90 & 18.18 \\
\hline & 7 & 6.0924 & 0.3474 & -1.3221 & 2.5290 & 3.83 & 4.26 & 4.90 & 6.06 & 8.15 & 11.67 & 19.75 \\
\hline & 7.5 & 6.2641 & 0.3640 & -1.2361 & 2.7759 & 3.86 & 4.30 & 4.96 & 6.24 & 8.58 & 12.51 & 21.34 \\
\hline & 8 & 6.4656 & 0.3805 & -1.1513 & 3.0269 & 3.90 & 4.35 & 5.05 & 6.45 & 9.07 & 13.41 & 22.83 \\
\hline & 8.5 & 6.6905 & 0.3963 & -1.0679 & 3.2661 & 3.95 & 4.41 & 5.15 & 6.68 & 9.59 & 14.29 & 24.02 \\
\hline & 9 & 6.9464 & 0.4105 & -0.9870 & 3.4737 & 4.01 & 4.49 & 5.28 & 6.94 & 10.12 & 15.12 & 24.80 \\
\hline & 9.5 & 7.2332 & 0.4223 & -0.9091 & 3.6298 & 4.09 & 4.59 & 5.43 & 7.23 & 10.66 & 15.86 & 25.18 \\
\hline & 10 & 7.5377 & 0.4317 & -0.8357 & 3.7182 & 4.18 & 4.71 & 5.61 & 7.54 & 11.18 & 16.49 & 25.34 \\
\hline & 10.5 & 7.8500 & 0.4388 & -0.7676 & 3.7348 & 4.27 & 4.84 & 5.80 & 7.85 & 11.66 & 17.05 & 25.46 \\
\hline & 11 & 8.1575 & 0.4441 & -0.7052 & 3.6890 & 4.37 & 4.98 & 5.99 & 8.16 & 12.11 & 17.53 & 25.60 \\
\hline & 11.5 & 8.4551 & 0.4477 & -0.6491 & 3.5998 & 4.46 & 5.11 & 6.19 & 8.46 & 12.52 & 17.95 & 25.77 \\
\hline & 12 & 8.7644 & 0.4495 & -0.6001 & 3.4892 & 4.56 & 5.26 & 6.40 & 8.76 & 12.92 & 18.35 & 26.00 \\
\hline & 12.5 & 9.1037 & 0.4494 & -0.5588 & 3.3729 & 4.70 & 5.44 & 6.65 & 9.10 & 13.34 & 18.79 & 26.34 \\
\hline & 13 & 9.4771 & 0.4476 & -0.5258 & 3.2654 & 4.86 & 5.66 & 6.93 & 9.48 & 13.79 & 19.28 & 26.77 \\
\hline & 13.5 & 9.8715 & 0.4441 & -0.5003 & 3.1753 & 5.05 & 5.90 & 7.24 & 9.87 & 14.26 & 19.79 & 27.26 \\
\hline & 14 & 10.2792 & 0.4393 & -0.4810 & 3.1074 & 5.26 & 6.16 & 7.56 & 10.28 & 14.74 & 20.30 & 27.74 \\
\hline & 14.5 & 10.6873 & 0.4334 & -0.4669 & 3.0654 & 5.50 & 6.44 & 7.89 & 10.69 & 15.22 & 20.80 & 28.18 \\
\hline & 15 & 11.0716 & 0.4272 & -0.4570 & 3.0425 & 5.73 & 6.70 & 8.21 & 11.07 & 15.66 & 21.25 & 28.56 \\
\hline & 15.5 & 11.4057 & 0.4219 & -0.4497 & 3.0273 & 5.93 & 6.94 & 8.49 & 11.41 & 16.04 & 21.65 & 28.91 \\
\hline & 16 & 11.6741 & 0.4182 & -0.4439 & 3.0112 & 6.09 & 7.13 & 8.71 & 11.67 & 16.36 & 21.98 & 29.23 \\
\hline & 16.5 & 11.8843 & 0.4163 & -0.4389 & 2.9901 & 6.21 & 7.27 & 8.88 & 11.88 & 16.61 & 22.27 & 29.55 \\
\hline & 17 & 12.0601 & 0.4156 & -0.4342 & 2.9646 & 6.30 & 7.38 & 9.01 & 12.06 & 16.83 & 22.54 & 29.90 \\
\hline & 17.5 & 12.2198 & 0.4158 & -0.4289 & 2.9386 & 6.37 & 7.47 & 9.14 & 12.22 & 17.04 & 22.81 & 30.26 \\
\hline & 18 & 12.3746 & 0.4158 & -0.4219 & 2.9175 & 6.44 & 7.56 & 9.25 & 12.37 & 17.24 & 23.06 & 30.56 \\
\hline & 18.5 & 12.5249 & 0.4154 & -0.4125 & 2.9008 & 6.51 & 7.65 & 9.37 & 12.52 & 17.42 & 23.28 & 30.79 \\
\hline & 19 & 12.6650 & 0.4149 & -0.4006 & 2.8872 & 6.57 & 7.73 & 9.47 & 12.67 & 17.59 & 23.45 & 30.94 \\
\hline & 19.5 & 12.7914 & 0.4146 & -0.3862 & 2.8775 & 6.62 & 7.80 & 9.57 & 12.79 & 17.75 & 23.60 & 31.04 \\
\hline \multirow[t]{27}{*}{ Male } & 6 & 5.2871 & 0.3836 & -1.0960 & 4.8016 & 3.21 & 3.51 & 4.05 & 5.29 & 7.70 & 11.28 & 17.20 \\
\hline & 6.5 & 5.5388 & 904 & -1.0977 & 5.0401 & 3.35 & 3.66 & 4.22 & 5.54 & 8.16 & 12.09 & 18.69 \\
\hline & 7 & 5.8079 & 0.3965 & -1.0994 & 5.2828 & 3.49 & 3.82 & 4.41 & 5.81 & 8.64 & 12.96 & 20.26 \\
\hline & 7.5 & 6.0797 & 0.4021 & -1.1001 & 5.5045 & 3.64 & 3.97 & 4.59 & 6.08 & 9.13 & 13.84 & 21.88 \\
\hline & 8 & 6.3370 & 0.4077 & -1.0994 & 5.6729 & 3.78 & 4.12 & 4.77 & 6.33 & 9.60 & 14.71 & 23.55 \\
\hline & 8.5 & 6.5751 & 0.4133 & -1.0974 & 5.7598 & 3.90 & 4.25 & 4.93 & 6.57 & 10.03 & 15.54 & 25.25 \\
\hline & 9 & 6.7747 & 0.4203 & -1.0946 & 5.7440 & 3.99 & 4.36 & 5.06 & 6.77 & 10.42 & 16.36 & 27.21 \\
\hline & 9.5 & 6.9283 & 0.4281 & -1.0916 & 5.6129 & 4.05 & 4.43 & 5.15 & 6.92 & 10.74 & 17.12 & 29.36 \\
\hline & 10 & 7.0323 & 0.4352 & -1.0889 & 5.3693 & 4.07 & 4.47 & 5.21 & 7.02 & 10.96 & 17.69 & 31.32 \\
\hline & 10.5 & 7.0859 & 0.4402 & -1.0870 & 5.0319 & 4.07 & 4.48 & 5.24 & 7.07 & 11.04 & 17.99 & 32.76 \\
\hline & 11 & 7.1096 & 0.4423 & -1.0872 & 4.6343 & 4.07 & 4.49 & 5.26 & 7.08 & 11.03 & 18.00 & 33.47 \\
\hline & 11.5 & 7.1329 & 0.4406 & -1.0906 & 4.2149 & 4.08 & 4.52 & 5.30 & 7.10 & 10.94 & 17.78 & 33.43 \\
\hline & 12 & & & -1.0971 & 3.8024 & 4.11 & 4.58 & 5.37 & 7.14 & 10.83 & 17.39 & \begin{tabular}{|l|}
32.71 \\
\end{tabular} \\
\hline & 12.5 & 7.2268 & 0.4254 & -1.1057 & 3.4165 & 4.17 & 4.66 & 5.46 & 7.19 & 10.69 & 16.88 & 31.45 \\
\hline & 13 & 7.2915 & 0.4130 & -1.1155 & 3.0718 & 4.24 & 4.76 & 5.57 & 7.26 & 10.54 & 16.30 & 29.85 \\
\hline & 13.5 & 7.3647 & 0.3986 & -1.1256 & 2.7784 & 4.33 & 4.88 & 5.70 & 7.33 & 10.40 & 15.71 & 28.13 \\
\hline & 14 & 7.4489 & 0.3831 & -1.1352 & 2.5417 & 4.44 & 5.01 & 5.85 & 7.42 & 10.28 & 15.16 & 26.46 \\
\hline & 14.5 & 7.5468 & 0.3677 & -1.1438 & 2.3642 & 4.56 & 5.15 & 6.00 & 7.52 & 10.20 & 14.71 & 24.97 \\
\hline & 15 & 7.6669 & 0.3533 & -1.1508 & 2.2436 & 4.70 & 5.31 & 6.16 & 7.65 & 10.18 & 14.39 & 23.76 \\
\hline & 15.5 & 7.8138 & 0.3410 & -1.1553 & 2.1705 & 4.85 & 5.47 & 6.34 & 7.80 & 10.24 & 14.23 & 22.92 \\
\hline & 16 & 7.9923 & 0.3316 & -1.1565 & 2.1345 & 5.01 & 5.64 & 6.52 & 7.98 & 10.37 & 14.24 & 22.45 \\
\hline & 16.5 & 8.2078 & 0.3247 & -1.1538 & 2.1262 & 5.18 & 5.83 & 6.73 & 8.20 & 10.59 & 14.39 & 22.30 \\
\hline & 17 & 8.4528 & 0.3197 & -1.1467 & 2.1359 & 5.36 & 6.03 & 6.94 & 8.44 & 10.86 & 14.65 & 22.35 \\
\hline & 17.5 & 8.7139 & 0.3161 & -1.1350 & 2.1547 & 5.55 & 6.23 & 7.17 & 8.71 & 11.17 & 14.98 & 22.53 \\
\hline & 18 & 8.9755 & 0.3145 & -1.1183 & 2.1759 & 5.72 & 6.42 & 7.38 & 8.97 & 11.50 & 15.35 & 22.83 \\
\hline & 18.5 & 9.2212 & 0.3145 & -1.0964 & 2.1938 & 5.87 & 6.59 & 7.58 & 9.22 & 11.82 & 15.73 & 23.20 \\
\hline & 19 & 9.4349 & 0.3157 & -1.0691 & 2.2048 & 5.98 & 6.72 & 7.75 & 9.43 & 12.10 & 16.08 & 23.54 \\
\hline
\end{tabular}




\section{Table 6(on next page)}

Parameter values $(\mu, \sigma, \nu, \tau)$ and percentiles of suprailiac skinfold thickness [mm] by age and sex for Canadian children and youth aged 6 to 19 years. 
1

\begin{tabular}{|c|c|c|c|c|c|c|c|c|c|c|c|c|}
\hline Sex & Age [years] & $\mu$ & $\sigma$ & $v$ & $\tau$ & $3^{\text {rd }}$ & $10^{\text {th }}$ & $25^{\text {th }}$ & $50^{\text {th }}$ & $7^{\text {th }}$ & 90 $^{\text {th }}$ & $97^{\text {th }}$ \\
\hline \multirow[t]{28}{*}{ Female } & 6 & 6.6972 & 0.4008 & -0.9029 & 3.3367 & 3.86 & 4.34 & 5.11 & 6.70 & 9.58 & 13.80 & 21.08 \\
\hline & 6.5 & 6.8654 & 0.4266 & -0.8326 & 3.4717 & 3.81 & 4.32 & 5.14 & 6.86 & 10.07 & 14.77 & 22.74 \\
\hline & 7 & 7.0730 & 0.4535 & -0.7626 & 3.6134 & 3.78 & 4.31 & 5.18 & 7.07 & 10.64 & 15.87 & 24.51 \\
\hline & 7.5 & 7.3765 & 0.4800 & -0.6931 & 3.7620 & 3.79 & 4.34 & 5.29 & 7.38 & 11.37 & 17.17 & 26.42 \\
\hline & 8 & 7.8030 & 0.5037 & -0.6240 & 3.9130 & 3.86 & 4.45 & 5.48 & 7.80 & 12.28 & 18.65 & 28.33 \\
\hline & 8.5 & 8.2923 & 0.5230 & -0.5551 & 4.0595 & 3.95 & 4.59 & 5.72 & 8.29 & 13.24 & 20.07 & 29.86 \\
\hline & 9 & 8.8705 & 0.5363 & -0.4870 & 4.1943 & 4.10 & 4.80 & 6.03 & 8.87 & 14.27 & 21.43 & 31.02 \\
\hline & 9.5 & 9.5357 & 0.5422 & -0.4201 & 4.3053 & 4.30 & 5.06 & 6.42 & 9.54 & 15.34 & 22.66 & 31.82 \\
\hline & 10 & 10.2176 & 0.5420 & -0.3544 & 4.3718 & 4.53 & 5.36 & 6.84 & 10.22 & 16.32 & 23.65 & 32.26 \\
\hline & 10.5 & 10.9024 & 0.5379 & -0.2901 & 4.3767 & 4.76 & 5.67 & 7.28 & 10.90 & 17.22 & 24.46 & 32.54 \\
\hline & 11 & 11.5991 & 0.5315 & -0.2274 & 4.3136 & 5.00 & 6.00 & 7.75 & 11.60 & 18.08 & 25.21 & 32.85 \\
\hline & 11.5 & 12.2912 & 0.5237 & -0.1671 & 4.1882 & 5.24 & 6.34 & 8.23 & 12.29 & 18.89 & 25.89 & 33.20 \\
\hline & 12 & 12.9890 & 0.5145 & -0.1106 & 4.0133 & 5.49 & 6.70 & 8.74 & 12.99 & 19.65 & 26.54 & 33.62 \\
\hline & 12.5 & 13.7280 & 0.5043 & -0.0598 & 3.8054 & 5.77 & 7.10 & 9.30 & 13.73 & 20.45 & 27.26 & 34.22 \\
\hline & 13 & 14.5051 & 0.4933 & -0.0163 & 3.5869 & 6.09 & 7.55 & 9.92 & 14.51 & 21.27 & 28.05 & 34.99 \\
\hline & 13.5 & 15.2862 & 0.4817 & 0.0199 & 3.3771 & 6.43 & 8.04 & 10.56 & 15.29 & 22.07 & 28.84 & 35.81 \\
\hline & 14 & 16.0317 & 0.4695 & 0.0499 & 3.1880 & 6.79 & 8.53 & 11.2 & 16.03 & 22.80 & 29.55 & 36.55 \\
\hline & 14.5 & 16.7126 & 0.4571 & 0.0748 & 3.0276 & 7.14 & 9.02 & 11.81 & 16.71 & 23.44 & 30.15 & 37.16 \\
\hline & 15 & 17.3039 & 0.4453 & 0.0953 & 2.8954 & 7.48 & 9.47 & 12.37 & 17.30 & 23.96 & 30.61 & 37.61 \\
\hline & 15.5 & 17.7850 & 0.4348 & 0.1126 & 2.7869 & 7.78 & 9.86 & 12.84 & 17.78 & 24.36 & 30.93 & 37.90 \\
\hline & 16 & 18.1484 & 0.4259 & 0.1274 & 2.6967 & 8.01 & 10.17 & 13.21 & 18.15 & 24.63 & 31.12 & 38.05 \\
\hline & 16.5 & 18.4145 & 0.4185 & 0.1401 & 2.6189 & 8.20 & 10.42 & 13.50 & 18.41 & 24.80 & 31.21 & 38.09 \\
\hline & 17 & 18.6318 & 0.4121 & 0.1503 & 2.5499 & 8.36 & 10.63 & 13.75 & 18.63 & 24.92 & 31.27 & 38.11 \\
\hline & 17.5 & 18.8355 & 0.4064 & 0.1579 & 2.4865 & 8.51 & 10.83 & 13.98 & 18.84 & 25.04 & 31.34 & 38.16 \\
\hline & 18 & 19.0186 & 0.4015 & 0.1640 & 2.4234 & 8.64 & 11.01 & 14.19 & 19.02 & 25.15 & 31.40 & 38.23 \\
\hline & 18.5 & 19.1639 & 0.3973 & 0.1694 & 2.3582 & 8.75 & 11.17 & 14.37 & 19.16 & 25.22 & 31.43 & 38.29 \\
\hline & 19 & 19.2661 & 0.3942 & 0.1752 & 2.2932 & 8.81 & 11.28 & 14.51 & 19.27 & 25.24 & 31.43 & 38.32 \\
\hline & 19.5 & 19.3275 & 0.3924 & 0.1820 & 2.2315 & 8.84 & 11.35 & 14.60 & 19.33 & 25.24 & 31.41 & 38.34 \\
\hline \multirow[t]{27}{*}{ Male } & 6 & 6.3018 & 0.5203 & -0.6962 & 6.1066 & 3.16 & 3.56 & 4.33 & 6.30 & 10.49 & 16.56 & 24.91 \\
\hline & 6.5 & 6.5930 & 0.5288 & -0.6668 & 6.2092 & 3.26 & 3.67 & 4.49 & 6.59 & 11.05 & 17.42 & 25.96 \\
\hline & 7 & 6.8933 & 0.5374 & -0.6381 & 6.3102 & 3.36 & 3.79 & 4.66 & 6.89 & 11.62 & 18.31 & 27.04 \\
\hline & 7.5 & 7.2022 & 0.5462 & -0.6105 & 6.4014 & 3.46 & 3.91 & 4.83 & 7.20 & 12.22 & 19.25 & 28.21 \\
\hline & 8 & 7.5126 & 0.5562 & -0.5844 & 6.4749 & 3.55 & 4.03 & 5.00 & 7.51 & 12.85 & 20.26 & 29.55 \\
\hline & 8.5 & 7.8236 & 0.5672 & -0.5608 & 6.5276 & 3.63 & 4.13 & 5.15 & 7.82 & 13.50 & 21.36 & 31.09 \\
\hline & 9 & 8.1293 & 0.5793 & -0.5399 & 6.5518 & 3.70 & 4.23 & 5.30 & 8.13 & 14.17 & 22.55 & 32.87 \\
\hline & 9.5 & 8.4238 & 0.5915 & -0.5219 & 6.5395 & 3.76 & 4.31 & 5.44 & 8.42 & 14.84 & 23.76 & 34.76 \\
\hline & 10 & 8.7035 & 0.6017 & -0.5068 & 6.4882 & 3.83 & 4.40 & 5.58 & 8.70 & 15.46 & 24.88 & 36.53 \\
\hline & 10.5 & 8.9678 & 0.6086 & -0.4954 & 6.4021 & 3.90 & 4.49 & 5.72 & 8.97 & 16.01 & 25.84 & 38.04 \\
\hline & 11 & 9.2171 & 0.6113 & -0.4875 & 6.2895 & 3.98 & 4.60 & 5.87 & 9.22 & 16.46 & 26.57 & 39.13 \\
\hline & 11.5 & 9.4540 & 0.6099 & -0.4830 & 6.1530 & 4.08 & 4.72 & 6.03 & 9.45 & 16.82 & 27.06 & 39.82 \\
\hline & 12 & 9.6782 & 0.6052 & -0.4808 & 5.9886 & 4.19 & 4.86 & 6.19 & 9.68 & 17.10 & 27.35 & 40.15 \\
\hline & 12.5 & 9.8876 & 0.5978 & -0.4800 & 5.7993 & 4.31 & 5.00 & 6.36 & 9.89 & 17.30 & 27.44 & 40.13 \\
\hline & 13 & 10.0850 & 0.5877 & -0.4799 & 5.5886 & 4.44 & 5.15 & 6.54 & 10.09 & 17.42 & 27.35 & 39.77 \\
\hline & 13.5 & 10.2667 & 0.5761 & -0.4790 & 5.3571 & 4.57 & 5.31 & 6.72 & 10.27 & 17.47 & 27.10 & 39.16 \\
\hline & 14 & 10.4305 & 0.5638 & -0.4759 & 5.1099 & 4.70 & 5.46 & 6.90 & 10.43 & 17.46 & 26.73 & 38.33 \\
\hline & 14.5 & 10.5803 & 0.5516 & -0.4696 & 4.8578 & 4.81 & 5.60 & 7.06 & 10.58 & 17.42 & 26.31 & 37.43 \\
\hline & 15 & 10.7272 & 0.5403 & -0.4599 & 4.6105 & 4.92 & 5.74 & 7.23 & 10.73 & 17.39 & 25.91 & 36.56 \\
\hline & 15.5 & 10.8808 & 0.5305 & -0.4468 & 4.3691 & 5.02 & 5.87 & 7.39 & 10.88 & 17.37 & 25.58 & 35.84 \\
\hline & 16 & 11.0471 & 0.5234 & -0.4305 & 4.1337 & 5.10 & 5.99 & 7.55 & 11.05 & 17.42 & 25.40 & 35.41 \\
\hline & 16.5 & 11.2298 & 0.5191 & -0.4113 & 3.9077 & 5.17 & 6.11 & 7.71 & 11.23 & 17.53 & 25.37 & 35.28 \\
\hline & 17 & 11.4314 & 0.5170 & -0.3898 & 3.6947 & 5.23 & 6.21 & 7.87 & 11.43 & 17.69 & 25.47 & 35.38 \\
\hline & 17.5 & 11.6547 & 0.5158 & -0.3666 & 3.4997 & 5.29 & 6.32 & 8.04 & 11.65 & 17.90 & 25.65 & 35.59 \\
\hline & 18 & 11.8974 & 0.5153 & -0.3423 & 3.3301 & 5.35 & 6.44 & 8.23 & 11.90 & 18.15 & 25.90 & 35.90 \\
\hline & 18.5 & 12.1575 & 0.5147 & -0.3177 & 3.1943 & 5.41 & 6.56 & 8.42 & 12.16 & 18.43 & 26.19 & 36.21 \\
\hline & 19 & 12.4347 & 0.5131 & -0.2935 & 3.0962 & 5.50 & 6.70 & 8.62 & 12.43 & 18.74 & 26.47 & 36.45 \\
\hline
\end{tabular}




\section{Table 7 (on next page)}

Parameter values $(\mu, \sigma, v, \tau)$ and percentiles of medial calf skinfold thickness [mm] by age and sex for Canadian children and youth aged 6 to 19 years. 
1

\begin{tabular}{|c|c|c|c|c|c|c|c|c|c|c|c|c|}
\hline Sex & Age [years] & $\mu$ & $\sigma$ & $v$ & $\tau$ & $3^{\text {rd }}$ & $10^{\text {th }}$ & $25^{\text {th }}$ & $50^{\text {th }}$ & $75^{\text {th }}$ & $90^{\text {th }}$ & $97^{\text {th }}$ \\
\hline \multirow[t]{28}{*}{ Female } & 6 & 8.8756 & 0.3546 & -0.1545 & 1.7494 & 4.67 & 5.76 & 7.09 & 8.88 & 11.20 & 14.12 & 18.13 \\
\hline & 6.5 & 9.2641 & 0.3628 & -0.1300 & 1.8386 & 4.79 & 5.92 & 7.33 & 9.26 & 11.80 & 14.90 & 19.06 \\
\hline & 7 & 9.6544 & 0.3713 & -0.1055 & 1.9318 & 4.91 & 6.08 & 7.56 & 9.65 & 12.41 & 15.70 & 20.00 \\
\hline & 7.5 & 10.0464 & 0.3798 & -0.0817 & 2.0269 & 5.02 & 6.23 & 7.79 & 10.05 & 13.03 & 16.52 & 20.95 \\
\hline & 8 & 10.4394 & 0.3880 & -0.0590 & 2.1171 & 5.13 & 6.38 & 8.02 & 10.44 & 13.65 & 17.34 & 21.91 \\
\hline & 8.5 & 10.8320 & 0.3960 & -0.0376 & 2.1960 & 5.23 & 6.53 & 8.24 & 10.83 & 14.28 & 18.16 & 22.88 \\
\hline & 9 & 11.2226 & 0.4034 & -0.0180 & 2.2604 & 5.33 & 6.67 & 8.47 & 11.22 & 14.89 & 18.97 & 23.85 \\
\hline & 9.5 & 11.6082 & 0.4099 & -0.0009 & 2.3108 & 5.43 & 6.82 & 8.70 & 11.61 & 15.49 & 19.76 & 24.81 \\
\hline & 10 & 11.9874 & 0.4154 & 0.0128 & 2.3480 & 5.54 & 6.98 & 8.93 & 11.99 & 16.07 & 20.52 & 25.75 \\
\hline & 10.5 & 12.3598 & 0.4200 & 0.0225 & 2.3743 & 5.65 & 7.14 & 9.17 & 12.36 & 16.63 & 21.27 & 26.67 \\
\hline & 11 & 12.7243 & 0.4237 & 0.0285 & 2.3936 & 5.77 & 7.30 & 9.41 & 12.72 & 17.17 & 21.99 & 27.57 \\
\hline & 11.5 & 13.0793 & 0.4265 & 0.0308 & 2.4083 & 5.90 & 7.47 & 9.64 & 13.08 & 17.69 & 22.68 & 28.45 \\
\hline & 12 & 13.4235 & 0.4281 & 0.0299 & 2.4180 & 6.04 & 7.65 & 9.88 & 13.42 & 18.18 & 23.33 & 29.28 \\
\hline & 12.5 & 13.7571 & 0.4283 & 0.0271 & 2.4199 & 6.19 & 7.84 & 10.13 & 13.76 & 18.64 & 23.93 & 30.05 \\
\hline & 13 & 14.0787 & 0.4274 & 0.0232 & 2.4129 & 6.36 & 8.04 & 10.38 & 14.08 & 19.06 & 24.47 & 30.74 \\
\hline & 13.5 & 14.3853 & 0.4249 & 0.0189 & 2.3988 & 6.53 & 8.25 & 10.63 & 14.39 & 19.44 & 24.93 & 31.33 \\
\hline & 14 & 14.6745 & 0.4210 & 0.0150 & 2.3798 & 6.71 & 8.47 & 10.88 & 14.67 & 19.77 & 25.31 & 31.78 \\
\hline & 14.5 & 14.9414 & 0.4156 & 0.0139 & 2.3578 & 6.90 & 8.69 & 11.13 & 14.94 & 20.04 & 25.59 & 32.08 \\
\hline & 15 & 15.1812 & 0.4092 & 0.0180 & 2.3359 & 7.08 & 8.90 & 11.37 & 15.18 & 20.25 & 25.76 & 32.20 \\
\hline & 15.5 & 15.3921 & 0.4024 & 0.0278 & 2.3153 & 7.25 & 9.10 & 11.58 & 15.39 & 20.41 & 25.85 & 32.19 \\
\hline & 16 & 15.5739 & 0.3958 & 0.0429 & 2.2962 & 7.39 & 9.27 & 11.77 & 15.57 & 20.53 & 25.88 & 32.07 \\
\hline & 16.5 & 15.7273 & 0.3898 & 0.0617 & 2.2790 & 7.51 & 9.41 & 11.94 & 15.73 & 20.62 & 25.87 & 31.91 \\
\hline & 17 & 15.8549 & 0.3849 & 0.0820 & 2.2666 & 7.59 & 9.53 & 12.07 & 15.85 & 20.7 & 25.84 & 31.74 \\
\hline & 17.5 & 15.9602 & 0.3811 & 0.1014 & 2.2608 & 7.66 & 9.62 & 12.18 & 15.96 & 20.76 & 25.83 & 31.61 \\
\hline & 18 & 16.0453 & 0.3785 & 0.1179 & 2.2603 & 7.70 & 9.68 & 12.26 & 16.05 & 20.82 & 25.84 & 31.52 \\
\hline & 18.5 & 16.1127 & 0.3774 & 0.1309 & 2.2605 & 7.73 & 9.72 & 12.32 & 16.11 & 20.89 & 25.88 & 31.50 \\
\hline & 19 & 16.1645 & 0.3779 & 0.1405 & 2.2579 & 7.72 & 9.74 & 12.35 & 16.16 & 20.95 & 25.95 & 31.57 \\
\hline & 19.5 & 16.2024 & 0.3800 & 0.1470 & 2.2522 & 7.69 & 9.72 & 12.36 & 16.20 & 21.02 & 26.06 & 31.71 \\
\hline \multirow[t]{28}{*}{ Male } & 6 & 7.6139 & 0.3532 & -0.4290 & 2.0886 & 4.25 & 5.03 & 6.05 & 7.61 & 9.82 & 12.62 & 16.57 \\
\hline & 6.5 & 7.9514 & 0.3740 & -0.4000 & 2.2278 & 4.30 & 5.11 & 6.21 & 7.95 & 10.47 & 13.61 & 17.96 \\
\hline & 7 & 8.3241 & 0.3942 & -0.3711 & 2.3743 & 4.37 & 5.21 & 6.38 & 8.32 & 11.18 & 14.70 & 19.45 \\
\hline & 7.5 & 8.7435 & 0.4118 & -0.3426 & 2.5227 & 4.47 & 5.34 & 6.59 & 8.74 & 11.95 & 15.84 & 20.96 \\
\hline & 8 & 9.1952 & 0.4264 & -0.3147 & 2.6629 & 4.58 & 5.50 & 6.84 & 9.20 & 12.75 & 17.00 & 22.45 \\
\hline & 8.5 & 9.6377 & 0.4404 & -0.2878 & 2.7854 & 4.69 & 5.64 & 7.07 & 9.64 & 13.55 & 18.14 & 23.92 \\
\hline & 9 & 10.0372 & 0.4568 & -0.2627 & 2.8827 & 4.75 & 5.74 & 7.25 & 10.04 & 14.31 & 19.31 & 25.50 \\
\hline & 9.5 & 10.3692 & 0.4757 & -0.2405 & 2.9490 & 4.75 & 5.78 & 7.38 & 10.37 & 15.02 & 20.46 & 27.15 \\
\hline & 10 & 10.6239 & 0.4941 & -0.2228 & 2.9851 & 4.71 & 5.78 & 7.45 & 10.62 & 15.62 & 21.48 & 28.69 \\
\hline & 10.5 & 10.7952 & 0.5074 & -0.2113 & 2.9966 & 4.68 & 5.77 & 7.49 & 10.80 & 16.03 & 22.21 & 29.84 \\
\hline & 11 & 10.9036 & 0.5136 & -0.2077 & 2.9961 & 4.67 & 5.79 & 7.53 & 10.90 & 16.27 & 22.62 & 30.50 \\
\hline & 11.5 & 10.9717 & 0.5145 & -0.2128 & 2.9980 & 4.71 & 5.82 & 7.58 & 10.97 & 16.39 & 22.83 & 30.84 \\
\hline & 12 & 11.0043 & 0.5115 & -0.2262 & 3.0093 & 4.76 & 5.87 & 7.62 & 11.00 & 16.43 & 22.88 & 30.95 \\
\hline & 12.5 & 10.9698 & 0.5073 & -0.2460 & 3.0302 & 4.81 & 5.90 & 7.63 & 10.97 & 16.35 & 22.80 & 30.88 \\
\hline & 13 & 10.8526 & 0.5017 & -0.2700 & 3.0602 & 4.84 & 5.90 & 7.58 & 10.85 & 16.15 & 22.51 & 30.54 \\
\hline & 13.5 & 10.6446 & 0.4947 & -0.2959 & 3.0972 & 4.83 & 5.86 & 7.48 & 10.64 & 15.79 & 22.00 & 29.86 \\
\hline & 14 & 10.3584 & 0.4868 & -0.3214 & 3.1372 & 4.80 & 5.77 & 7.32 & 10.36 & 15.31 & 21.30 & 28.89 \\
\hline & 14.5 & 10.0042 & 0.4798 & -0.3446 & 3.1788 & 4.71 & 5.64 & 7.11 & 10.00 & 14.75 & 20.47 & 27.75 \\
\hline & 15 & 9.6173 & 0.4750 & -0.3643 & 3.2226 & 4.58 & 5.46 & 6.85 & 9.62 & 14.15 & 19.64 & 26.61 \\
\hline & 15.5 & 9.2415 & 0.4714 & -0.3799 & 3.2679 & 4.45 & 5.28 & 6.60 & 9.24 & 13.59 & 18.85 & 25.52 \\
\hline & 16 & 8.9001 & 0.4694 & -0.3911 & 3.3148 & 4.31 & 5.10 & 6.37 & 8.90 & 13.09 & 18.15 & 24.57 \\
\hline & 16.5 & 8.5901 & 0.4703 & -0.3978 & 3.3649 & 4.17 & 4.92 & 6.14 & 8.59 & 12.66 & 17.59 & 23.82 \\
\hline & 17 & 8.3241 & 0.4727 & -0.4010 & 3.4191 & 4.03 & 4.76 & 5.93 & 8.32 & 12.32 & 17.15 & 23.24 \\
\hline & 17.5 & 8.1317 & 0.4742 & -0.4017 & 3.4752 & 3.93 & 4.64 & 5.79 & 8.13 & 12.06 & 16.81 & 22.75 \\
\hline & 18 & 8.0090 & 0.4733 & -0.4007 & 3.5298 & 3.88 & 4.57 & 5.70 & 8.01 & 11.88 & 16.53 & 22.31 \\
\hline & 18.5 & 7.9196 & 0.4702 & -0.3983 & 3.5766 & 3.86 & 4.53 & 5.64 & 7.92 & 11.73 & 16.25 & 21.81 \\
\hline & 19 & 7.8366 & 0.4643 & -0.3943 & 3.6102 & 3.84 & 4.51 & 5.60 & 7.84 & 11.55 & 15.90 & 21.17 \\
\hline & 19.5 & 7.7663 & 0.4572 & -0.3887 & 3.6266 & 3.84 & 4.50 & 5.57 & 7.77 & 11.37 & 15.55 & 20.53 \\
\hline
\end{tabular}

